\title{
Phf21b imprints the spatiotemporal epigenetic switch essential for neural stem cell differentiation
}

\author{
Amitava Basu, ${ }_{1}^{1}$ Iván Mestres, ${ }^{2}$ Sanjeeb Kumar Sahu, ${ }^{3}$ Neha Tiwari, ${ }^{4}$ Bimola Khongwir, ${ }^{1}$ Jan Baumgart, ${ }^{5}$ \\ Aditi Singh, ${ }^{6}$ Federico Calegari, ${ }^{2}$ and Vijay K. Tiwari ${ }^{6}$ \\ ${ }^{1}$ Institute of Molecular Biology, 55128 Mainz, Germany; ${ }^{2}$ Center for Regenerative Therapies Dresden (CRTD), School of Medicine, \\ Technische Universität Dresden, 01307 Dresden, Germany; ${ }^{3}$ Salk Institute for Biological Studies, La Jolla, California 92037, USA; \\ ${ }^{4}$ Institute of Physiological Chemistry, University Medical Center Johannes Gutenberg-University Mainz, 55128 Mainz, Germany; \\ ${ }^{5}$ Translational Animal Research Center (TARC), University Medical Centre, Johannes Gutenberg-University, 55131 Mainz, \\ Germany; ${ }^{6}$ Wellcome-Wolfson Institute for Experimental Medicine, School of Medicine, Dentistry, and Biomedical Science, \\ Queens University Belfast, Belfast BT9 7BL, United Kingdom
}

Cerebral cortical development in mammals involves a highly complex and organized set of events including the transition of neural stem and progenitor cells (NSCs) from proliferative to differentiative divisions to generate neurons. Despite progress, the spatiotemporal regulation of this proliferation-differentiation switch during neurogenesis and the upstream epigenetic triggers remain poorly known. Here we report a cortex-specific PHD finger protein, Phf21b, which is highly expressed in the neurogenic phase of cortical development and gets induced as NSCs begin to differentiate. Depletion of Phf21b in vivo inhibited neuronal differentiation as cortical progenitors lacking Phf21b were retained in the proliferative zones and underwent faster cell cycles. Mechanistically, Phf21b targets the regulatory regions of cell cycle promoting genes by virtue of its high affinity for monomethylated H3K4. Subsequently, Phf21b recruits the lysine-specific demethylase Lsd1 and histone deacetylase Hdac2, resulting in the simultaneous removal of monomethylation from H3K4 and acetylation from H3K27, respectively. Intriguingly, mutations in the Phf21b locus associate with depression and mental retardation in humans. Taken together, these findings establish how a precisely timed spatiotemporal expression of Phf21b creates an epigenetic program that triggers neural stem cell differentiation during cortical development.

[Keywords: cortical development; epigenetics; genomics; gene regulation; neurogenesis]

Supplemental material is available for this article.

Received October 18, 2019; revised version accepted July 21, 2020.

The development of the mammalian cerebral cortex is a highly coordinated process that relies on a complex interplay between a variety of regulatory factors including epigenetic regulators and transcriptional factors that control gene expression (Guillemot et al. 2006; Itoh et al. 2013; Florio and Huttner 2014; Imayoshi and Kageyama 2014; Shibata et al. 2015; Thakurela et al. 2015; Pataskar et al. 2016; Urbán et al. 2016; Kishi and Gotoh 2018; Tsuboi et al. 2018; Zhang et al. 2019). During embryonic development of the mammalian brain, neural stem and progenitor cells (NSC) progressively switch from proliferative to differentiative divisions to generate neurons and glia that populate the cortical layers. The molecular control of the switch from proliferation to differentiation is of vital importance for proper neurogenesis during cortical development (Dehay and Kennedy 2007; Herrup and Yang 2007;

Corresponding author: v.tiwari@qub.ac.uk

Article published online ahead of print. Article and publication date are online at http://www.genesdev.org/cgi/doi/10.1101/gad.333906.119.
Orford and Scadden 2008; Hardwick et al. 2015). Misregulation of molecules involved in these cortical development pathways is known to be associated with cortical malformations caused by abnormal proliferation, migration defects or altered connectivity (Guerrini and Parrini 2010; Wollnik 2010; Bozzi et al. 2012; Yang et al. 2012; Gilmore and Walsh 2013; Homem et al. 2015). The regulation of cell cycle, specifically the G1 phase, was also shown to play a crucial role in controlling area-specific rates of neuron production and the generation of cytoarchitectonic maps (Dehay and Kennedy 2007). For example, lengthening G1 of neural stem and progenitor cells triggered premature neurogenesis (Calegari and Huttner 2003), while shortening G1 inhibited neurogenesis and promoted the

(C) 2020 Basu et al. This article is distributed exclusively by Cold Spring Harbor Laboratory Press for the first six months after the full-issue publication date (see http://genesdev.cshlp.org/site/misc/terms.xhtml). After six months, it is available under a Creative Commons License (Attribution-NonCommercial 4.0 International), as described at http://creativecommons.org/licenses/by-nc/4.0/. 
expansion of the progenitor pool (Lange et al. 2009; Pilaz et al. 2009). Several factors are well characterized to control the progression through G1, including retinoblastoma $(\mathrm{Rb})$, which becomes hyperphosphorylated and allows E2F transcription factors to induce several downstream targets, notably cyclins, required for cell cycle progression (Poppy Roworth et al. 2015). However, despite an increased understanding of the downstream gene regulatory programs controlling cell cycle progression (Lee 1997; Shibata et al. 2015), the upstream epigenetic triggers that initiate the Rb-E2F cascade and essential for NSC differentiation and brain development remain elusive.

The PHD proteins comprise an important set of epigenetic readers that are known to play diverse roles including in cell cycle regulation in different contexts (Baker et al. 2008; Gatchalian et al. 2016). Along these lines, genetic aberrations that target PHD fingers of certain genes (e.g., RAG2, ING, NSD1, and ATRX) have been associated with a wide range of human pathologies including immunological disorders, cancers, and neurological diseases, potentially arising from a misinterpretation of epigenetic marks (Baker et al. 2008). Depending on the stoichiometry, the PHD proteins recognize specific histone modifications and regulate gene expression (Sanchez and Zhou 2011). For example, PHD fingers from BPTF and ING2 recognize H3K4me3 mark (Jones et al. 2000; Lan et al. 2007), while the PHD fingers in BHC80 and DNMT3L bind to unmodified histone $\mathrm{H} 3$ tails. Interestingly, a PHD protein Phf6 also regulates neuronal migration and its mutations are associated with intellectual disability (Zhang et al. 2013). Another PHD protein Phf21a (Bhc80) was shown to recognize H3K4me0 (Lan et al. 2007) and repress nonneuronal genes in cooperation with REST (Monaghan et al. 2017). However, the expression pattern of $\mathrm{Phf} 21$ a is not brain-specific and Phf2la knockout mice died due to suckling dysfunction without any noticeable brain defects (Iwase et al. 2006).

Here we used a comprehensive bioinformatics analysis in combination with global gene expression profiling of several tissues derived from the three germ layers, which revealed certain PHD finger proteins that are specifically expressed during cortical development. We found one such protein, Phf $21 \mathrm{~b}$ (plant-homeodomain finger protein $21 \mathrm{~b}$ ), originally proposed as a tumor suppressor (Bertonha et al. 2015), to be highly expressed in the neurogenic phase of cortical development and induced as NSCs begin to differentiate. A mechanistic analysis showed that Phf $21 \mathrm{~b}$ targets H3K4mel mark present at the promoters of cell cycle promoting genes and subsequently recruits lysinespecific demethylase Lsd1 and histone deacetylase $\mathrm{Hdac} 2$ to these sites resulting in the simultaneous removal of monomethylation from $\mathrm{H} 3 \mathrm{~K} 4$ as well as acetylation from H3K27. The consequential repression of cell cycle promoting genes allow neural progenitors to exit proliferation and differentiate into neurons. These molecular findings were further validated by phenotypic characterization following Phf21b depletion during cortical development where cortical progenitors lacking Phf $21 \mathrm{~b}$ showed retention in the proliferative zones and exhibited an accelerated cell cycle. Overall, our findings establish Phf $21 \mathrm{~b}$ as a master regulator of cortical development by controlling the epigenetic program underlying the spatiotemporal switch from proliferation to differentiation during neurogenesis. Corroborating our findings of a critical role of Phf21b during cortical development, a deletion encompassing PHF21B locus was shown to be associated with the neurodevelopmental disorder Phelan-McDermid syndrome (Sarasua et al. 2014) and a rare single nucleotide variation near PHF21B gene was linked with an increased risk of major depressive disorder (Wong et al. 2017).

\section{Results}

Phf21b is induced during neurogenesis and exhibits $a$ distinct spatiotemporal expression pattern

In search of novel PHD-containing proteins relevant for embryonic neurogenesis, we compiled a list of 75 candidates using Interpro database (Hunter et al. 2009) and analyzed the expression of the corresponding genes using transcriptome (RNA-seq) data sets of several tissues during development including the cortical areas ventricular zone (VZ), subventricular zone (SVZ), and cortical plate $(\mathrm{CP})$ as well as the specific cell populations of proliferative versus neurogenic progenitors and neurons (Fietz et al. 2012; Aprea et al. 2013). This revealed that 27 out of 75 PHD-containing genes are expressed at higher levels in the cortex compared with other tissues (Fig. 1A; Supplemental Fig. S1a). Out of the 27 shortlisted genes, 10 were not expressed or very lowly expressed in VZ and 13 were not differentially expressed. Of the remaining four genes, we shortlisted Phf21b for further investigation given its genetic association with a neurodevelopmental disorder (Phelan-McDermid syndrome) as well as depression in humans. Surprisingly, no study has investigated the function of Phf $21 \mathrm{~b}$ in cortical development, or its role as an epigenetic regulator in any other context.

Phf 21 b contains a single PHD and a nuclear localization signal (NLS) predicted at its $\mathrm{N}$ terminal end (Fig. 1B). In situ hybridization data (Visel 2004) allowed us to validate the expression of $P h f 21 b$ selectively within the cortex and primarily in neuronal layers relative to the germinal zones (Fig. 1C). By taking advantage of previous transcriptome studies of the developing cortex (Fietz et al. 2012; Aprea et al. 2013), we found that $P h f 21 b$ was expressed at higher levels in the basal radial glial cells (bRG) as compared with the apical radial glial cells (aRG) and maintained at high levels in neurons (Fig. 1D). In line with these observations, Phf21b was up-regulated during the switch of proliferating progenitors to differentiating progenitors and kept being highly expressed in neurons (Fig. 1D). In addition, expression of Phf $21 \mathrm{~b}$ also included cells within the intermediate zone (IZ) and newly formed neurons as validated by immunohistochemistry of the E14.5 cortex (Fig. 1E,F; Supplemental Fig. S1b,c).

Further analysis with the Genevestigator software showed that Phf 21 b expression is highest in the early stages of brain development, which gradually declines in the later stages and is severely reduced in the postnatal brain (Supplemental Fig. S1d). In line with these findings, 
A PHD Finger domain containing proteins

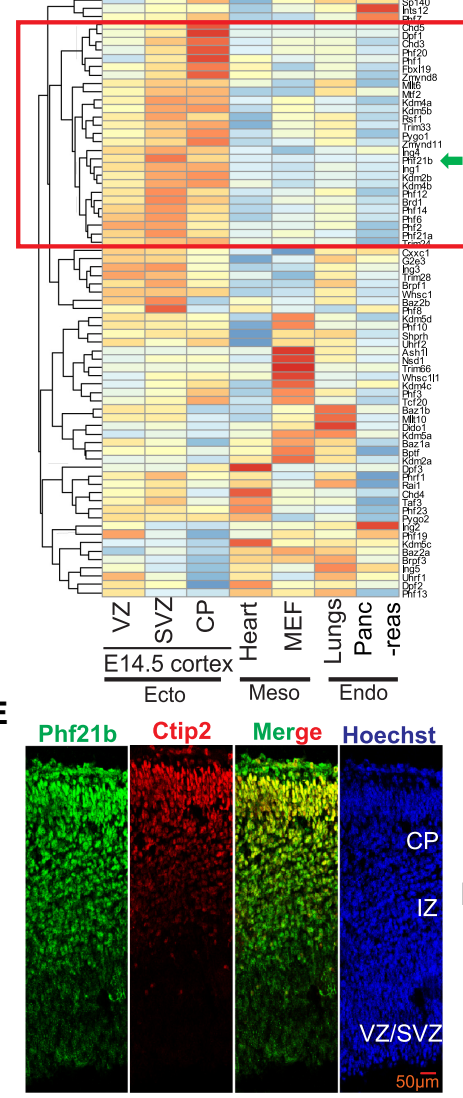

B

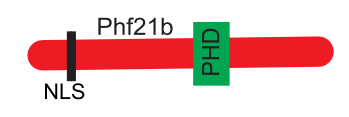

C

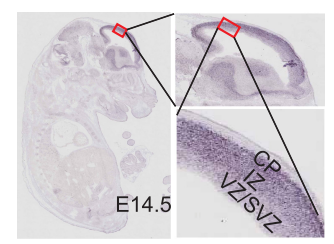

D
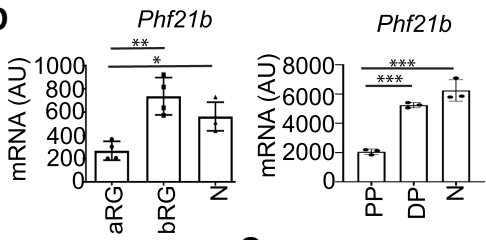

$\mathbf{F} \frac{\infty}{\bar{d}} 60 \frac{* * *}{* * *} \mathbf{G}$

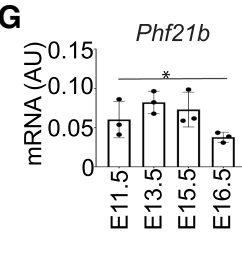

H
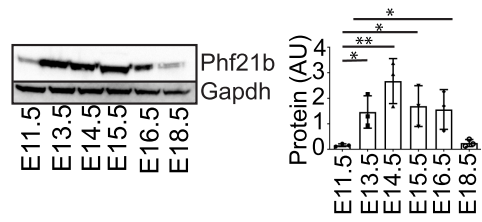

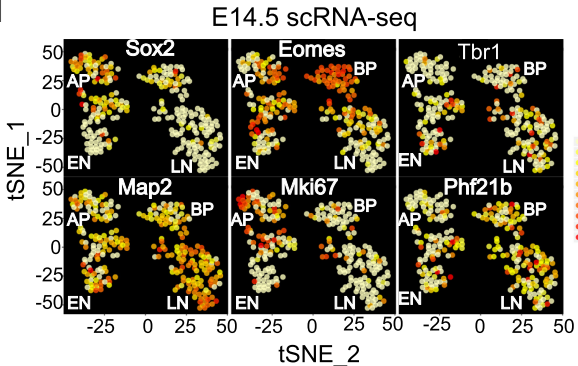

J $\quad$ E14.5 scRNA-seq

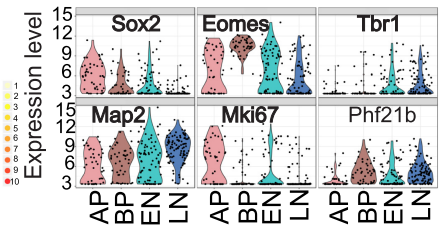

tex (Telley et al. 2016). (J) Violin plots showing the expression levels of distinct markers in the same data as in $I$.

Phf21b expression peaked only during the neurogenic phase of cortical development (E11.5-E15.5) and gradually diminished as the astrogliogenic phase started (Fig. 1G, $\mathrm{H}_{\text {; }}$ Supplemental Fig. S1b-d; Tiwari et al. 2018).

Using an existing data of single-cell RNA sequencing at high temporal resolution tracking the lineage of the molecular identities of successive generations of apical progenitors (APs) and their daughter neurons in mouse embryos (Telley et al. 2016), we confirmed Phf21b induction as cells transit from an AP to a BP state, which then continues to be expressed in early and late neurons in distinct subpopulations (Fig. 1I,J). These data further show that the cells that express $P h f 21 b$ do not express proliferative markers such as Mki67 while they begin to coex-
Figure 1. Phf21b is induced during neurogenesis and exhibits a distinct spatiotemporal expression pattern during cortical development. (A) Heat map of expression of plant homeotic domain (PHD)-containing proteins in different tissues from an E14.5 mouse embryo taken from Interpro database (Hunter et al. 2009; Fietz et al. 2012; Aprea et al. 2013). The red box includes a subset of highlighted proteins that are enriched in the cortex. (B) Representation of Phf21b protein showing PHD and nuclear localization signal (NLS). (C) Phf21b in situ hybridization in the E14.5 mouse embryo (Visel 2004). Zoomed inset shows the Phf21b expression in different cortical layers of the cortex. $(D)$ Phf21b expression in RNA-seq data sets from different public data sets (Fietz et al. 2012; Aprea et al. 2013). The plots with normalized tag count for Phf21b are shown for apical radial glial cells $\left(\mathrm{aRG}, \mathrm{DiI}^{+}\right.$, Proml ${ }^{+}$, and Tubb3$\mathrm{GFP}^{-}$), basal radial glial cells (bRG, $\mathrm{DiI}^{+}$, Prom1and Tubb3-GFP ${ }^{-}$, and neurons ( $\mathrm{N}, \mathrm{DiI}^{+}$, Tubb3$\mathrm{GFP}^{+}$, and Prom $\left.^{-}\right)(n=4)$; proliferating progenitors (PP), which lacked neural progenitor marker Btg2 as well as postmitotic neuronal marker Tubb3; and differentiating progenitors (DP), which lacked neural progenitor marker Btg2 but had postmitotic neuronal marker Tubb3 or neurons (N). $(n=3)(E)$ Immunostaining of mouse E14.5 cortex showing Phf21b, deep neuronal marker Ctip2 and Hoechst (nucleus). (F) Plot from E14.5 immunostained cortex showing percentage of $\mathrm{Ph} 21 \mathrm{~b}$ immunostained present across the three cortical layers ventricular/ subventricular zone (VZ/SVZ), intermediate zone (IZ), and cortical plate (CP) $(n=4$, derived from at least four embryos obtained from four different litters). (G) Phf21b expression in RNA-seq data sets from cortex for different stages of mouse embryonic development $(n=3)$. (H) Immunoblot assays showing Phf21b expression in the cortex during different stages of mouse embryonic development $(n=3)$ along with quantitation of the same. (I) tSNE plots showing the expression of various markers in apical progenitor (AP), basal progenitor (BP), early neuron (EN), and late neuron (LN) subpopulations as defined in the single-cell RNA sequencing data from the developing neocor- press early-born postmitotic neuronal marker Tbr1. Altogether, these data suggest that Phf $21 \mathrm{~b}$ expression is highly controlled in a spatiotemporal fashion to potentially allow its function in the neurogenic phase of cortical development.

\section{Depletion of Phf21b impairs neurogenesis in vivo}

We next attempted to investigate the potential role of Phf21b during cortical development. Therefore, we performed in utero electroporation (IUE) assay in mouse cortex at E13.5 using either a control or an shRNA plasmid against Phf21 $\mathrm{b}$ as described previously (Lange et al. 2009). This shRNA construct was found to trigger a significant 
reduction in Phf21b expression (Supplemental Fig. S2a-c). Further analysis of cortices derived $4 \mathrm{~d}$ after electroporation showed an expected pattern of neurogenesis for progenitor cells targeted with a control shRNA by contributing cells throughout the entire cortex (Lange et al. 2009). Interestingly however, Phf21b-depleted cells were retained at a higher proportion in the subventricular and intermediate zones as identified by immunostaining for the SVZ and basal progenitor marker Tbr2 and early-born neuronal marker Ctip2 (Fig. 2A,B,D; Supplemental Fig. S2d-h). The quantifications of these cells revealed that Phf $21 \mathrm{~b}$ depleted cells were impaired in exiting the basal progenitor state $\left(\mathrm{Tbr}^{+}\right)$and acquiring a neuronal fate $\left(\mathrm{Ctip}^{+}\right)$in the absence of Phf $21 \mathrm{~b}$ (Fig. 2B; Supplemental Fig. S2d,e). Furthermore, Phf21b knockdown cells showed an increased percentage of cells expressing the progenitor marker Pax6 (Supplemental Fig. S2g-i). Altogether, these observations suggested retention in the progenitor state in the absence of Phf $21 \mathrm{~b}$ and impaired neurogenesis.

We next aimed to assess the specificity of the observed phenotype by complementing the loss-of-function assays with a rescue experiment. Indeed, the retention of Phf21b-depleted cells in the germinal zones could be significantly rescued by coelectroporating a plasmid containing an shRNA-resistant cDNA for Phf21b (Fig. 2C, D; Supplemental Fig. S2c). These observations confirmed that the observed phenotype was specifically resulting from the loss of Phf21b during cortical development. Importantly, further confirming our observations, the overexpression of Phf $21 \mathrm{~b}$ alone led to the converse phenotype and a higher number of electroporated cells in the CP along with a corresponding reduction in the germinal zones of the cortex (Supplemental Fig. S3a-e). In summary, our observations suggest that Phf $21 \mathrm{~b}$ is a novel essential regulator of neurogenesis during cortical development.

\section{Loss of Phf21b up-regulates neuronal progenitor genes} and down-regulates neuronal differentiation genes

We next attempted to decipher the molecular program that underlies the observed defects on corticogenesis following Phf21b depletion. Toward this, we repeated electroporation as described earlier and FAC-sorted control and Phf21b-depleted cortical cells to perform RNA-seq analyses (Fig. 3A). Further bioinformatics assessment of these data revealed a marked misregulation of several genes (up-regulated $=470$; down-regulated $=266$ ) upon Phf21b knockdown (Fig. 3B; Supplemental Table S1). A noticeably larger number of up-regulated genes as compared with down-regulated genes following the loss of Phf21b implied that Phf21b potentially functions as a transcriptional repressor. Importantly, gene ontology analysis revealed that genes associated with neuronal differentiation such as NeuroD1, Cux2 were enriched among down-regulated genes, while cell adhesion, extracellular matrix organization, and cell cycle genes such as Ccnd1, Fzd6, and Sox2 were abundant among up-regulated genes (Fig. 3C,D). Analysis of expression dynamics of up-regulated and down-regulated genes during neurogenesis in vivo showed that the derepressed genes were expressed at a much higher level in aRG (apical radial glia) during cortical development, while down-regulated genes were expressed at a higher level in neurons (Fig. 3E). Intriguingly, the promoter regions of up-regulated genes showed a high enrichment for motifs for critical cell cycle regulators such as E2F1 and E2F7, etc., suggesting that these positive regulators of cell cycle progression were induced by these transcription factors upon Phf21b knockdown (Fig. $3 \mathrm{~F})$. Overall, $\mathrm{Phf} 21 \mathrm{~b}$ is essential to repress the proliferation program and steer the cell fate toward neuronal differentiation during cortical development.

It is possible that the gene expression differences observed above result from an unequal proportion of
A
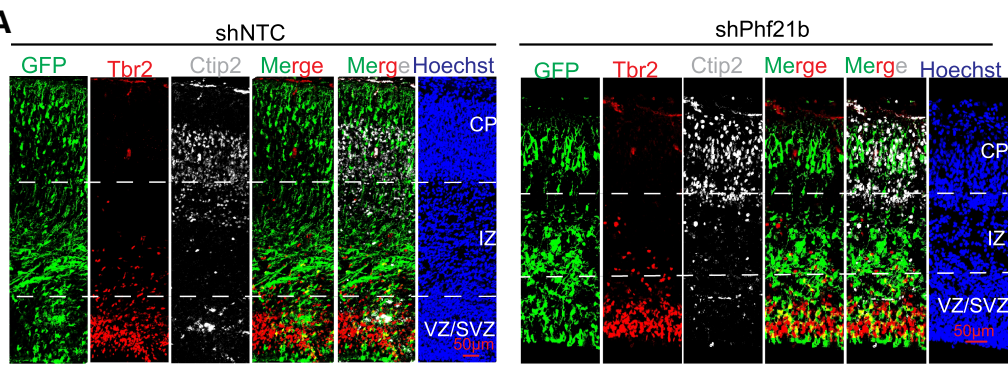

B

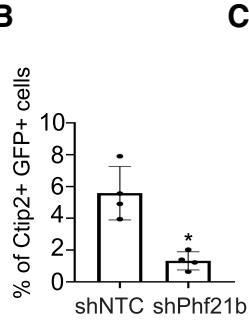

C $_{\text {shPhf21b (GFP) }+ \text { Phf21b OE (RFP) }}$

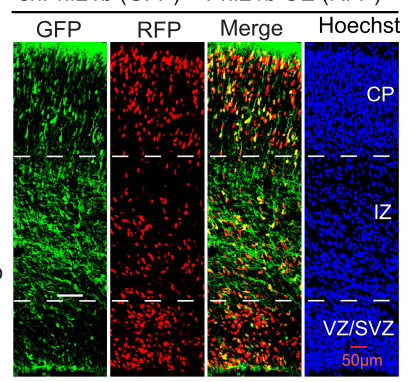

D

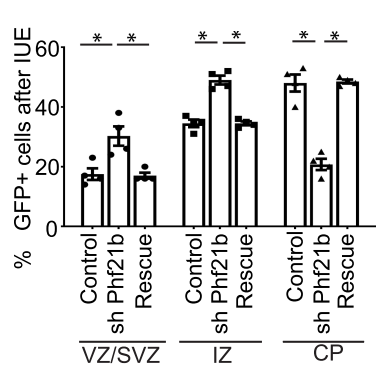

Figure 2. Phf $21 \mathrm{~b}$ is required for proper neurogenesis. (A) Cortical sections immunostained at mouse E17.5 stage after IUE with shPhf21b GFP or shNTC GFP constructs at E13.5 stage. Immunostaining was performed with GFP antibody as well as SVZ marker Tbr2 and neuronal marker Ctip2. (B) Plot showing percentage of Ctip2 positive cells amongst the electroporated cells in control and Phf21b knockdown condition. Data are represented as mean $\pm \mathrm{SD}$ from four embryos obtained from four different litters. Two-sided Mann-Whitney $U$-test. $\left({ }^{*}\right) P<0.05$. (C) Cortical sections showing coelectroporated shPhf21b GFP and Phf21b RFP plasmids in E17.5 cortex showing successful rescue of the phenotype. $(D)$ Graphical representation of quantitation of electroporated cells across three different bins in the mouse cortex after IUE to knockdown, overexpressing or rescue Phf21b phenotype. Data are represented as mean \pm SD from four embryos obtained from four different litters. Two-sided Mann-Whitney $U$ test. $\left(^{*}\right) P<0.05$. 
progenitor cells and differentiated neurons between the control and Phf21b-depleted cortex. Therefore, we extended our in vivo analyses to an established models of in vitro neuronal differentiation in which Neuro2A cells can be differentiated into neurons by serum starvation and addition of retinoic acid. Interestingly, a siRNA-mediated depletion of Phf $21 \mathrm{~b}$ during neuronal differentiation in these in vitro model systems lead to an impaired neuronal differentiation as marked by a decreased network formation (Supplemental Fig. S4a). To gain further insights into the altered gene expression program, we performed genomewide transcriptome profiling (RNA-seq) following Phf21b knockdown (Supplemental Fig. S4b). A principle component analysis (PCA) showed a clear blockage in differentiation program upon knockdown of Phf21b (Supplemental Fig. S4b) with a differential expression of 291 down-regulated and 470 up-regulated genes (Supplemental Fig. S4c; Supplemental Table S2). In line with our findings in vivo, loss of Phf $21 \mathrm{~b}$ led to a much higher number of up-regulated genes, corroborating its function as a repressor, and these genes were enriched for several cell cycle promoting genes including E2F1, E2F7, Ccnd1, Mcm5, etc., which are known to be physiologically silenced during neurogenesis as cells achieve a postmitotic fate (Supplemental Fig. S4c,d; Dehay and Kennedy 2007; Frank and Tsai 2009; Kaldis and Richardson 2012; Tsume et al. 2012; Magri et al. 2014; Homem et al. 2015). In contrast, down-regulated genes were enriched for neurogenesis-related GO terms such as nervous system development, cell differentiation, and neuron migration and included important neuronal markers including Tubb2b and Mapt, etc. As expected, the derepressed genes were found

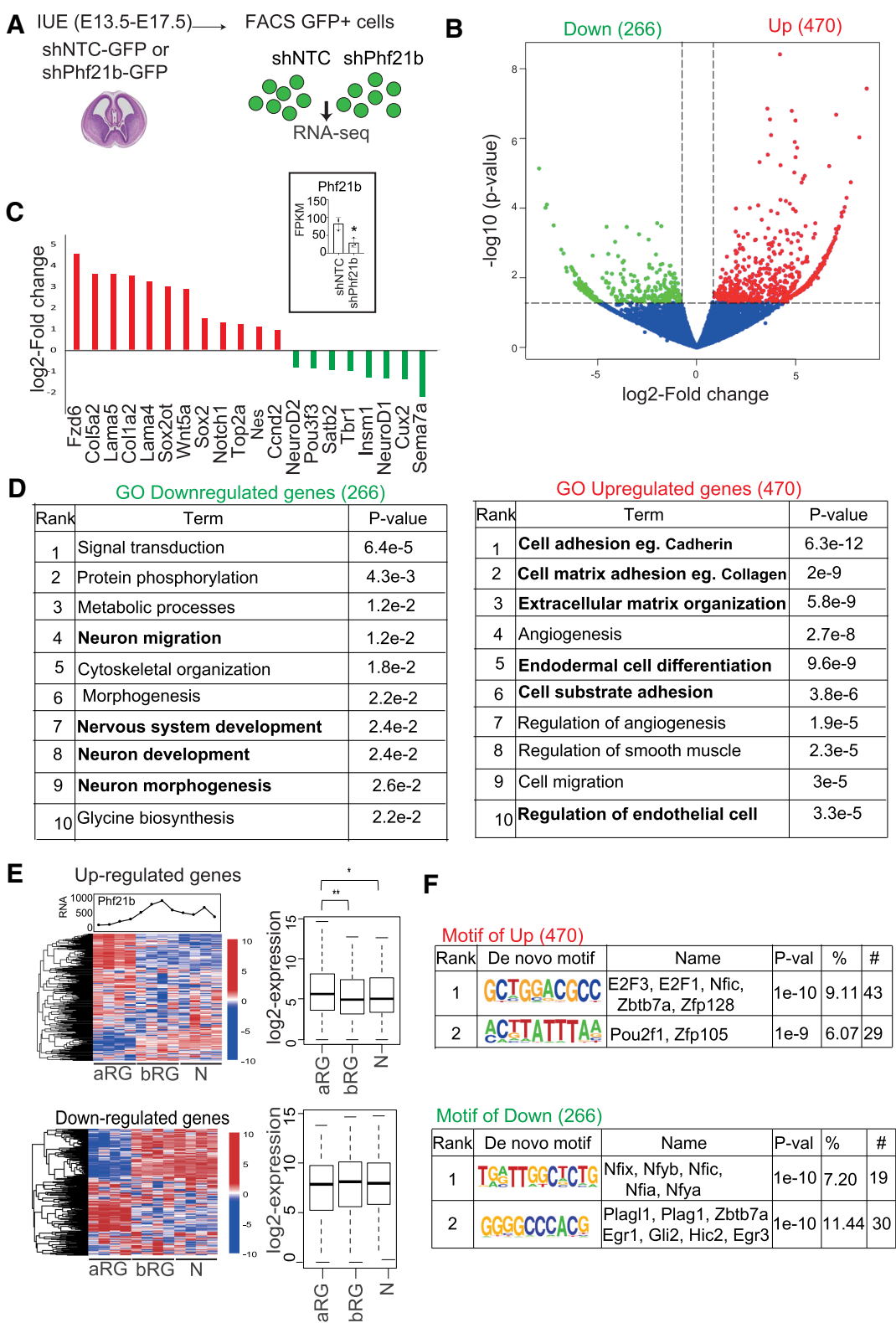

Figure 3. Phf $21 \mathrm{~b}$ is essential for repression of cell cycle genes during neurogenesis. (A) Schematic representation showing IUE with control or shPhf21b-GFP plasmids followed by FACS sorting and RNA-seq analysis $(n=3)$. The E14.5 cortex image was downloaded from the EMAGE database (Richardson et al. 2014). (B) Volcano plot representing the differential expression of genes on Phf $21 \mathrm{~b}$ knockdown. (C) Bargraph showing the $\log 2$-fold changes of the representative genes from known apical progenitor cells as well as genes involved in neuronal differentiation. Inset shows Phf21b knockdown efficiency from data in $B$. (D) Top enriched genes for biological processes were visualized along with their $P$-values. (E) Heat map showing the dynamics of up-regulated and down-regulated genes during neurogenesis in vivo. The cell populations were derived from E14.5 cortex and defined as explained in the legend for Figure 1D. We made use of this publically available transcriptome data for analyzing gene expression dynamics of genes regulated by Phf21b.The same information is presented as a box plot as well. $\left(^{*}\right) P<0.05$; $\left(^{* *}\right) P<0.01$. $(F)$ Table representing de novo motifs enriched at the promoter regions of misregulated genes. The percentage $(\%)$ and the number (\#) of DEGs, which have the corresponding motif in the promoter regions, are indicated. 
to be expressed at a higher level in aRG compared with neurons during cortical development (Supplemental Fig. S4e). On the other hand, the down-regulated genes exhibited a higher expression in neurons as compared with aRG, confirming compromised neurogenesis in the absence of Phf21b (Supplemental Fig. S4e). Thus, in vitro neuronal differentiation of Neuro2a could closely recapitulate our observations in vivo.

Interestingly, ectopic expression of Phf21b in embryonic stem cells did not cause any noticeable transcriptional change, implying that Phf21b function is restricted to neuronal somatic stem cells and other cell type-specific regulatory factors may play a role in its function during cortical development (Supplemental Fig. S4f,g). Overall, the observed molecular changes corroborate and extend the phenotypic changes observed following Phf21b depletion highlighting Phf $21 \mathrm{~b}$ as an essential factor triggering the exit from a proliferative state toward differentiation and neurogenesis during cortical development.

\section{Phf21b promotes cell cycle exit during neurogenesis}

The targeting and activation of positive regulators of cell cycle progression and the concomitant inhibition of neurogenesis observed upon Phf21b knockdown (Fig. 2A) very well fitted with the concept that a shorter G1 promotes the expansion of neural progenitors at the expense of neurogenic divisions (Dehay and Kennedy 2007; Lange and Calegari 2010; Salomoni and Calegari 2010). Our previous analyses, however, were insufficient to infer whether or not the cell cycle was in fact shortened by Phf21b knockdown. Hence, we repeated in utero electroporation as described above but this time sacrificing the mice at E15.5 rather than E17.5 as a means to detect earlier, acute effects on cell cycle length. This was assessed by combining electroporation with the well-established approach of cumulative and mitotic thymidine labeling by designing a unique protocol in which BrdU was administered cumulatively for either $3 \mathrm{~h}$ (Borrell and Calegari 2014) or $9 \mathrm{~h}$, and EdU was given to the same mice for the last $2 \mathrm{~h}$ prior to sacrifice (Fig. 4A; Calegari 2005; Arai et al. 2011). Specifically, these labeling times were chosen as ideal to detect shorter than physiological cell cycles as based on previous reports assessing the proliferative activity of progenitor types of the developing mouse cortex (Calegari 2005; Arai et al. 2011).

Brains targeted with control or Phf $21 \mathrm{~b}$ shRNA constructs were then processed to reveal BrdU/EdU incorporation within GFP+ targeted cells as a function of time. Importantly, since progenitor subtypes are known to
A
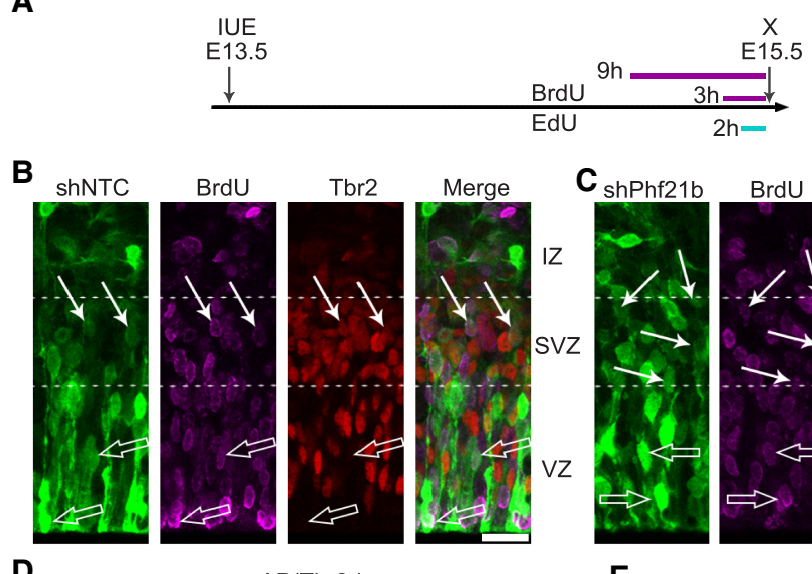

AP(Tbr2-)

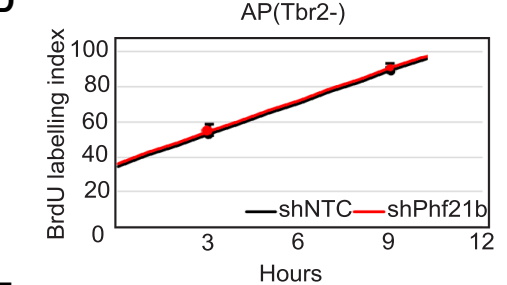

$\mathbf{F}$

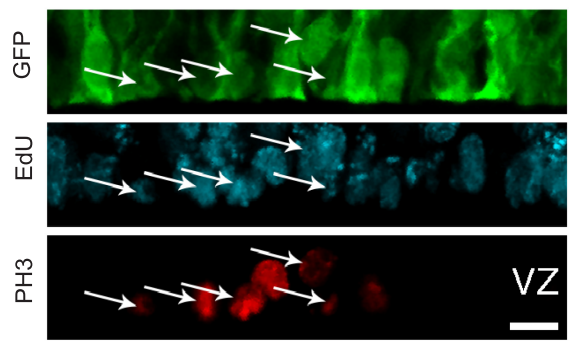

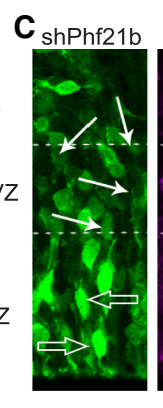
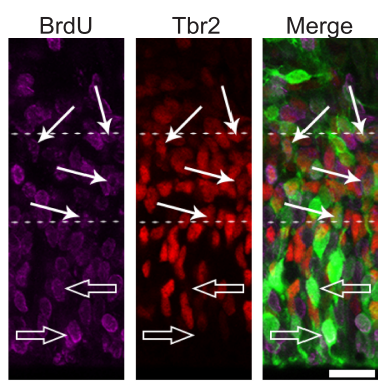

E

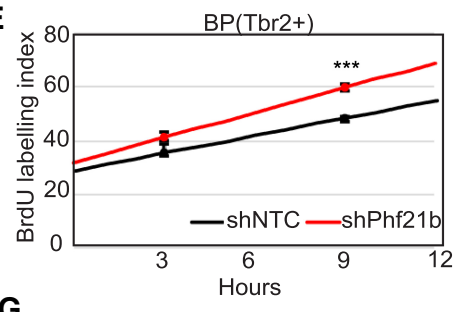

G

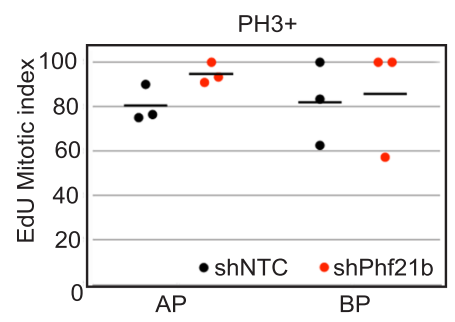

Figure 4. Phf $21 \mathrm{~b}$ is essential for cell cycle exit during neurogenesis. (A) Scheme indicating the paradigm used. In utero electroporation was conducted at E13.5. Cumulative BrdU (magenta lines) was injected either 3 or $9 \mathrm{~h}$ before sacrifice at E15.5 (X). Single injections of EdU (cyan lines) were administered $4 \mathrm{~h}$ before sacrifice. $(B, C)$ Representative brain slices electroporated either with shNTC or shPhf $21 \mathrm{~b}$ (green) subjected to cumulative BrdU injections for $9 \mathrm{~h}$, and counterstained for BrdU (magenta) and Tbr2 (red). Empty arrows point to apical progenitors $\left(\mathrm{Tbr}^{-}\right)$, which incorporated BrdU. Arrows indicate basal progenitors $\left(\mathrm{Tbr}^{+}\right)$that incorporated BrdU. $(D, E)$ BrdU labeling index for apical progenitors (Tbr2 ${ }^{-}$) or basal progenitors $\left(\mathrm{Tbr}^{+}\right) .\left(^{* * *}\right) P=0.0007, t$ test. Data are represented as mean \pm SD from at least three embryos obtained from three different litters. $(F)$ High-power image at the ventricular border of an electroplated brain subjected to EdU injection $4 \mathrm{~h}$ before sacrifice. Counterstains show EdU (cyan) and PH3 (red). $(G)$ Apical progenitors EdU mitotic index for the indicated time points using Tbr2 staining. Scale bars: $B, C, D, 20 \mu \mathrm{m}$. 
differ in their cell cycle parameters (Calegari 2005; Arai et al. 2011), we performed these quantifications independently in the two subpopulations of apical radial glia and basal progenitors as identified by Tbr2 immunostaining in the VZ and/or SVZ (Fig. 4B,C) with the latter being expected to have longer cell cycles than the former in physiological conditions (Arai et al. 2011).

Assessment of the cumulative BrdU labeling index at 3 and $9 \mathrm{~h}$ among the subpopulation of $\mathrm{Tbr} 2^{-}$apical radial glia in the VZ very well fitted with previous studies (Calegari 2005; Arai et al. 2011), but showed no difference with regard to the use of control versus Phf $21 \mathrm{~b}$ shRNA vectors (Fig. 4D). In contrast, remarkably, an increased slope in the labeling index as a function of labeling time was found upon Phf21b knockdown, specifically among Tbr2 ${ }^{+}$basal progenitors in the VZ/SVZ and indicative of a shorter cell cycle relative to electroporation with control vectors (Fig. 4E).

In addition, and again in line with previous studies (Calegari 2005; Arai et al. 2011), EdU labeling within the subpopulation of electroporated cells undergoing mitosis $\left(\mathrm{PH}^{+} / \mathrm{GFP}^{+}\right)$at the apical boundary of the $\mathrm{VZ}$ or within the SVZ indicated that saturation of labeling was essen- tially reached at $2 \mathrm{~h}$ both in apical and basal progenitors upon electroporation with either control or Phf $21 \mathrm{~b}$ shRNA vectors (Fig. 4F,G) and allowing us to exclude effects of our manipulation on the length of the G2-M phases.

In conclusion, our data showed that Phf $21 \mathrm{~b}$ affects cell cycle length specifically within the subpopulation of neurogenic, basal progenitors, but not radial glial cells.

\section{Phf21b associates with epigenetic repressors}

Driven by our observations that Phf 21 b represses cell cycle genes to promote cell cycle exit and neuronal differentiation during cortical development, we next aimed to decode the molecular mechanisms through which it attains these functions. Toward this, we sought to identify proteins associating with $\mathrm{Phf} 21 \mathrm{~b}$ by immunoprecipitation of Phf21b followed by quantitative mass spectrometry (IP-MS) of Neuro2A cells (Fig. 5A). Interestingly, this analysis revealed a number of epigenetic regulators that directly associated with Phf21b including histone deacetylase Hdac2 and lysine-specific demethylase Kdmla (Lsd1), which is known for its demethylation activity of
A

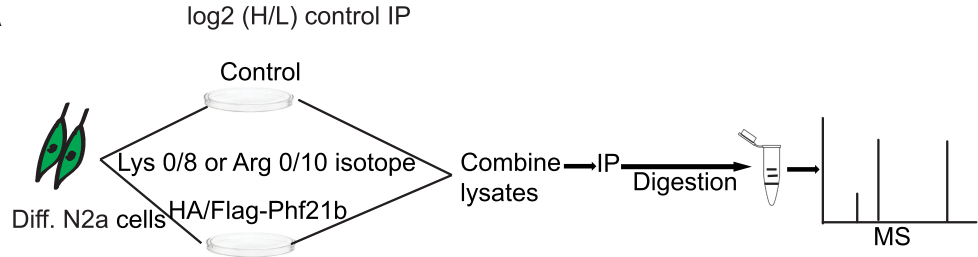

B

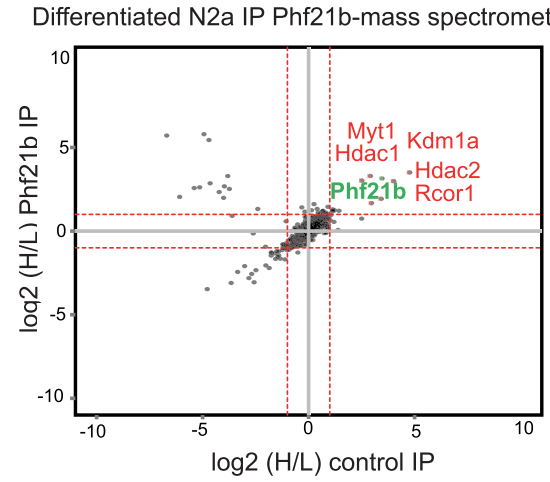

D

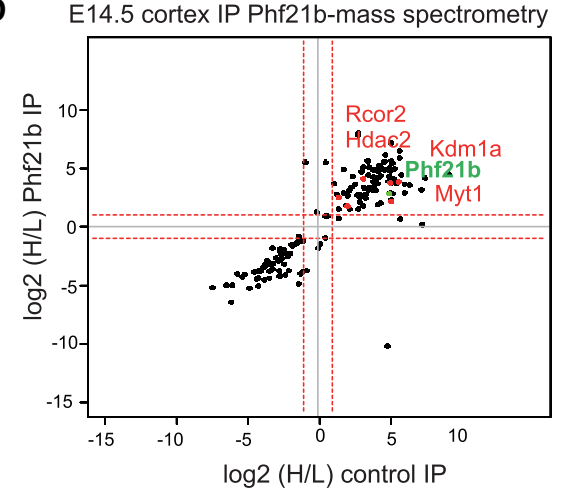

$\mathbf{E}$

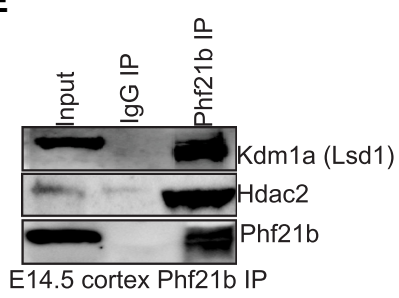

E14.5 cortex Phf21b IP

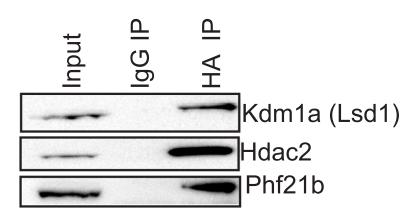

Differentiated N2a Phf21b IP
Figure 5. Phf21b associates with repressive epigenetic machinery. (A) Scheme for SILAC IPmass spectrometry in vitro using HA-Flag Phf21b transfected plasmid in differentiated N2a day 2 cells. $(B)$ Scatter plot for interacting partners identified in vitro using Flag antibody IP in N2a cells transfected with HA/Flag-Phf21b construct. Ratio $\mathrm{H} / \mathrm{L}$ denotes the ratio between two heavy and light label partners. (C) Western blot validation of interacting partners identified in vitro in N2a cells. (D) Scatter plot representation of the interacting partners identified from in vivo E14.5 cortex using endogenous Phf $21 \mathrm{~b}$ antibody IP followed by mass spectrometry. The partners enriched over control IgG IP is represented. $(E)$ Validation of the interacting partners identified from in vivo IP mass-spectrometry using immunoblotting with Phf21b antibody. 
H3K4me1/2 as well as H3K9me2 (Fig. 5B; Supplemental Table S3; Lee et al. 2005; Iwase et al. 2006). In addition, the complex also contained Myt1 and Rcor2, which are known to be essential during neurogenesis (Fig. 5B; Supplemental Fig. S5a; Vasconcelos et al. 2016; Wang et al. 2016; Mall et al. 2017). The interaction of Phf21b with $\mathrm{Kdm} 1 \mathrm{a}$ and Hdac2 was further validated by independent immunoprecipitation experiments (Fig. 5C). We next attempted to extend these observations in vivo and performed IP mass-spectrometry using protein extracts derived from E14.5 cortex. In line with the findings in vitro, Phf 21 b occurred in a complex with Hdac2 as well as Lsd1, which was independently validated using independent immunoprecipitation assays followed by Western blot analyses (Fig. 5D,E; Supplemental Fig. S5b; Supplemental Table S4). Altogether, these findings established that Phf $21 b$ associates with the components of the repressive epigenetic machinery and potentially use these in the repression of cell cycle genes during neurogenesis.

\section{Phf21b preferentially targets transcription start sites of genes}

We next asked whether Phf21b directly targets chromatin for gene regulation. To address this, we performed chromatin immunoprecipitation for Phf $21 \mathrm{~b}$ during neuronal differentiation in vitro, followed by next-generation sequencing (ChIP-seq). Interestingly, a genomewide analysis showed that $\mathrm{Phf} 2 \mathrm{lb}$ preferentially targeted the transcriptional start sites (Fig. 6A,B). Using a previously published ChIP-seq data set for Lsd1 from E13.5 cortex (Zhang et al. 2014), we found that nearly $50 \%$ of the

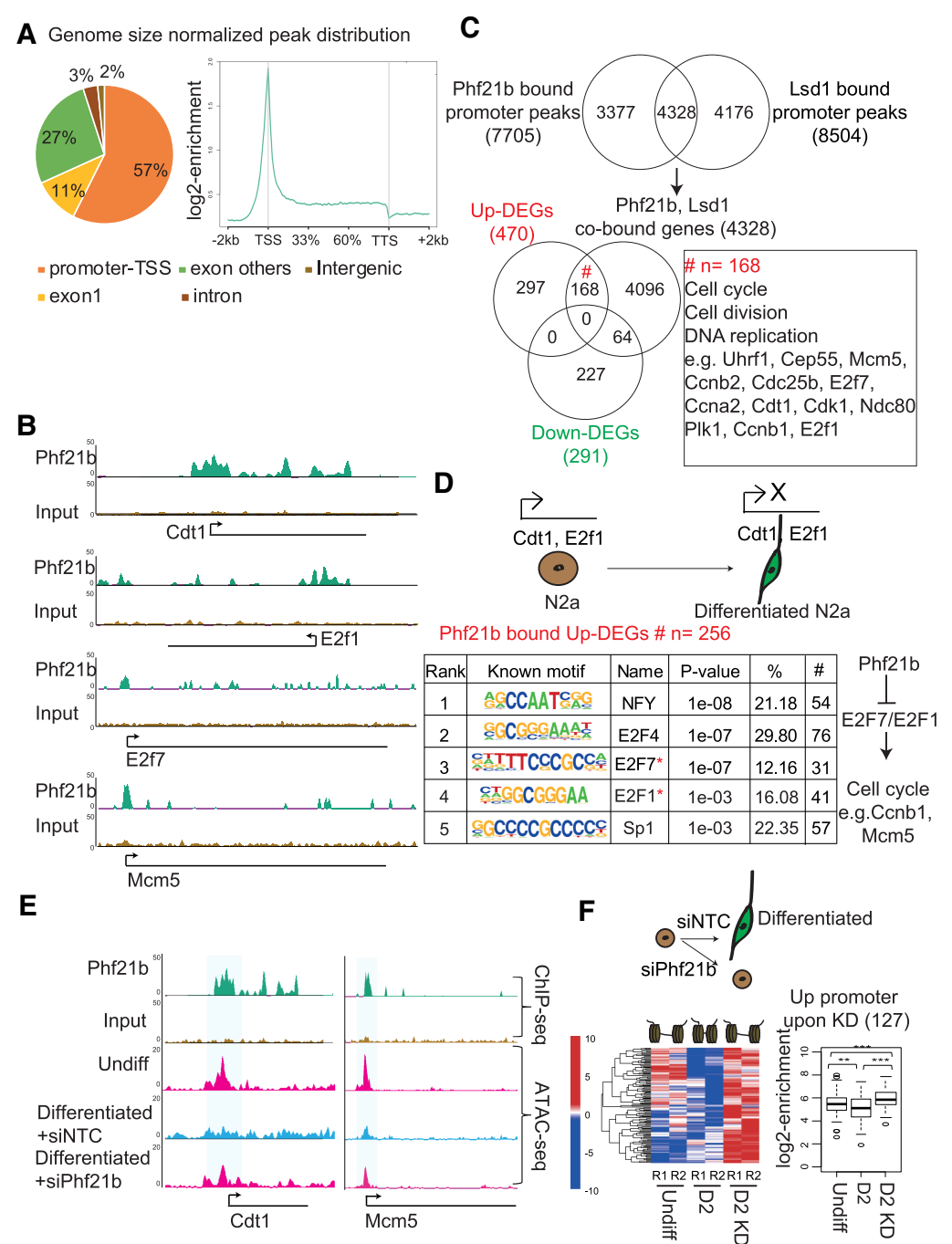

Figure 6. Phf $21 \mathrm{~b}$ preferentially targets transcription start sites of genes. (A) A pie chart depicting the distribution of $\mathrm{Phf} 21 \mathrm{~b}$ peaks $(n=41,815)$ across different genomic categories (promoters, exon1, exon others, intergenic regions, and introns) normalized by genome size in differentiated N2a day 2 cells after ChIP-seq. The right panel shows the density of Phf $21 \mathrm{~b}$ ChIP-seq enrichment between $2 \mathrm{~kb}$ upstream of TSS and $2 \mathrm{~kb}$ downstream from TTS $(n=1)$. (B) UCSC genome browser screenshots showing enrichment of Phf $21 \mathrm{~b}$ at representative target promoters. $(C)$ Venn diagram showing the overlap between Phf21b-bound promoter peaks (7705) and Lsd1-bound promoter peaks (8504). The lower Venn diagram depicts the overlap between Phf21b, Lsd1-cobound genes, and DEGs upon depletion of Phf21b in N2a cells. Some up-regulated DEGs overlapping with ChIP peaks are highlighted. $(D)$ The illustration at the top represents a possible mechanism for cell cycle regulation from undifferentiated to differentiated N2a cells. Table representing known motifs enriched at the Phf21b, Lsd1-cobound peaks in the promoter region of up-regulated DEGs from N2a RNA-seq data. The percentage $(\%)$ and the number (\#) of DEGs, which have the corresponding motif in the promoter regions, are indicated. $(E)$ UCSC genome browser screenshots representing the Phf $21 b$ ChIP enrichment and ATAC enrichment in the promoter region of representative genes in undifferentiated $\mathrm{N} 2 \mathrm{a}$, day 2 differentiated $\mathrm{N} 2 \mathrm{a}$ with control and and siPhf21b $(n=2)$. In the experiment with undifferentiated N2a cells, we did not add retinoic acid and hence they were not induced toward neuronal differentiation. The actual control to focus in these two experiments is siNTC (control siRNA) treated N2a cells where retinoic acid is added to induce neuronal differentiation. The test experiment is where N2a cells were treated with siPhf21b (siRNA against

Phf21b) and induced to differentiate to neurons by the addition of retinoic acid. These experimental settings were aimed to show that upon depletion of Phf21b, these cells appear similar to undifferentiated N2a cells (not treated with retinoic acid) and are unable to differentiate even in the presence of retinoic acid due to actively transcribing cell cycle genes, which cannot be turned off in the absence of Phf21b. $(F)$ Heat map showing the dynamics of ATAC enrichment in the 127 up-regulated peaks upon Phf21b depletion. The same information is presented as a box plot. $\left(^{* *}\right) P<0.01 ;\left({ }^{* * *}\right) P<0.001$. (R1) Replicate 1 ; (R2) replicate 2; (D2) day 2 differentiated N2a cells with retinoic acid. 
Lsd1 target sites were co-occupied by Phf21b (Fig. 6C; Supplemental Table S5). To further shortlist genes under their direct transcriptional control, we overlapped genes misregulated upon Phf $21 \mathrm{~b}$ depletion in N2a cells with those cobound by Phf $21 \mathrm{~b}$ and Lsd1. Interestingly, a significantly higher fraction of up-regulated genes showed overlap with Phf $21 \mathrm{~b}$ and Lsd 1 compared with down-regulated genes, in line with our earlier observations of a repressive function of Phf21b. Gene ontology enrichment analysis showed that the up-regulated genes cobound by Phf $21 \mathrm{~b}$ and Lsd1 were enriched for cell cycle genes; e.g., Cdk1, E2f7, E2f1, Cdt1, Ccna2, Ccnb1, Ccnb2, Cep55, Mcm5, Cdc25b, Ndc80, Plk1, and Uhrf1 (Fig. 6C; Supplemental Fig. S6a). Further analysis revealed that their promoter regions contained motifs enriched for E2F1 and E2F7 (Fig. 6D). This was interesting as E2F1 itself was derepressed following the loss of Phf21b, which subsequently causes up-regulation of its downstream target cell cycle promoting genes and in turn explaining the observed effect on shortening the cell cycle of neural progenitor cells upon Phf $21 \mathrm{~b}$ knockdown in vivo (Fig. 4). In line with these observations, we also observed an increase in the levels of phosphorylated retinoblastoma $(\mathrm{Rb})$ following Phf21b depletion (Supplemental Fig. S6b). Importantly, Phf21b was recruited to its target sites only upon onset of neurogenesis and not in undifferentiated cells (Supplemental Fig. S6c). Interestingly further, Phf21b lacking the PHD showed a significantly impaired recruitment to these sites, confirming that the PHD has a critical role in the chromatin targeting and function of Phf21b during neurogenesis (Supplemental Fig. S6d).

Our observations implied that $\mathrm{Phf} 2 \mathrm{lb}$ is targeted to cell cycle genes during neuronal differentiation for their transcriptional regulation. Assuming that such mechanisms would impact chromatin compaction, we decided to use ATAC-seq assay to assess chromatin accessibility at Phf21b target genes during neuronal differentiation in N2a cells as well as following Phf21b depletion during the same process. These data showed that the promoters of a majority of these genes exhibit an open chromatin state in undifferentiated cells in agreement with their actively transcribed state (Fig. 6E,F). Furthermore, retinoic acid-induced neuronal differentiation of these cells accompanied a loss of chromatin accessibility at these regions, in line with their transcriptional silencing upon acquisition of a neuronal fate (Fig. 6E,F). Importantly however, these loci retained open chromatin when Phf21b is depleted during this process (Fig. 6E). Altogether, these observations implied that Phf $21 \mathrm{~b}$ targets transcription start sites of distinct genes during neuronal differentiation triggering epigenetic remodeling for their repression.

Phf21b uses its PHD to recognize monomethylated lysine 4 at histone $H 3$ and repress cell cycle genes to promote cell cycle exit

Since Phf21b protein harbors a PHD, we were keen to investigate whether it has an affinity for any specific histone modifications and whether this is linked to its gene regu- latory function during neurogenesis. Toward this, we tested the affinity of Phf $21 \mathrm{~b}$ protein with specific histone modifications and their combinations using modified histone peptide array (Supplemental Fig. S7a; Dhayalan et al. 2011; Flynn et al. 2015). Interestingly, this analysis revealed that Phf $21 \mathrm{~b}$ has the strongest preference for monomethylation of lysine 4 at histone $\mathrm{H} 3$ (H3K4me1), followed by dimethylation of lysine 9 at histone H3 (H3K9me2) (Fig. 7A). This was particularly interesting as Lsd1, one of the interacting partners of Phf $21 \mathrm{~b}$, is known to demethylate these two modifications (Metzger et al. 2005; Forneris et al. 2006). The control array with purified GST or Phf21b protein lacking PHD did not show specificity toward any particular histone modification(s) (Supplemental Fig. S7b,c) confirming its specific affinity for distinct histone modifications.

To further validate these findings, we attempted to perform pulldown assays using biotinylated modified histone peptides with GST-tagged purified Phf21b protein (Supplemental Fig. S7d). In line with our findings from histone peptide array, the recombinant $\mathrm{Phf} 21 \mathrm{~b}$ recognized H3K4me1 as well as unmodified histone $\mathrm{H} 3$ peptide with the highest affinity (Fig. 7B). Importantly, Phf21b protein lacking the PHD as well as control GST protein did not exhibit binding to any histone peptides (Fig. 7B). Overall, our findings reveal $\mathrm{Phf} 2 \mathrm{lb}$ as an epigenetic reader with a specific and strong affinity for H3K4me1 mark.

Given the discovered role of Phf21b in repressing cell cycle genes during neurogenesis and the affinity of its PHD to H3K4me1 (Fig. 7B), we next aimed to characterize the contribution of the PHD in Phf21b-dependent cell cycle regulation during neuronal differentiation. Toward this, N2a cells were transfected with RFP-tagged control, Phf21b- and PHD-deleted Phf21b overexpression constructs and differentiated into neuronal cells for further functional analysis (Fig. 7C). In line with our earlier observations, the overexpression of Phf $21 \mathrm{~b}$ led to a significant reduction in the overall number of cells as compared with the control (Fig. 7D). In contrast, Phf 21 b protein lacking the PHD failed to elicit this effect under similar conditions (Fig. 7D). Immunofluorescence analysis with the neuronal marker Tuj1 further revealed an enhanced neuronal differentiation in Phf21b overexpressing cells as marked by an increased percentage of cells exhibiting longer neuronal projections (Fig. 7E,F). These effects were not visible in cells overexpressing Phf 21 b lacking the PHD and appeared identical to the control cells. For a better characterization of these effects, we carried out cell cycle profiling following BrdU labeling during differentiation of N2a cells overexpressing Phf21b, Phf21b lacking the PHD, and the control. Phf $21 \mathrm{~b}$ overexpression led to a significant increase in the proportion of cells in the G1 phase and a corresponding decrease in the S and G2 phases of cell cycle as compared with the control cells (Fig. 7G). On the contrary, overexpression of the Phf21b lacking PHD showed a cell cycle profile that was indistinguishable from the control cells. Last, we investigated whether these effects involved changes in the expression of cell cycle genes that were targeted by $\mathrm{Phf} 21 \mathrm{~b}$ and repressed during neurogenesis. Interestingly, while we observed a 
A

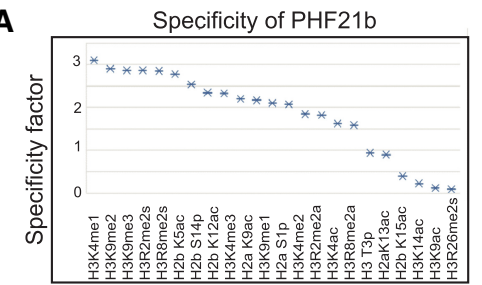

C

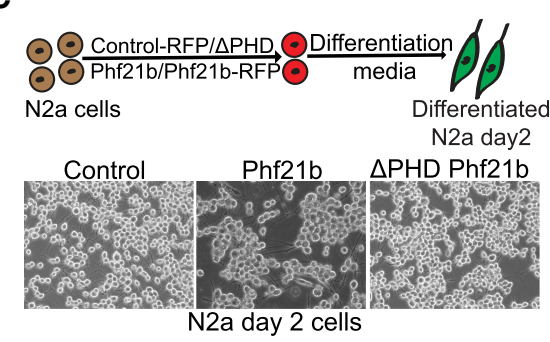

E

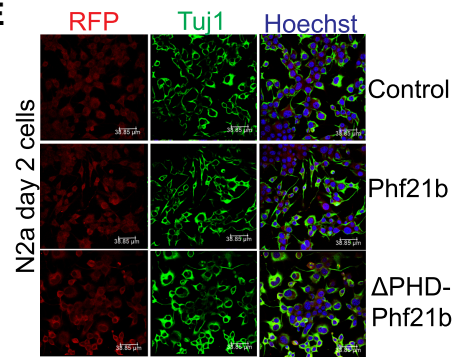

G N2a

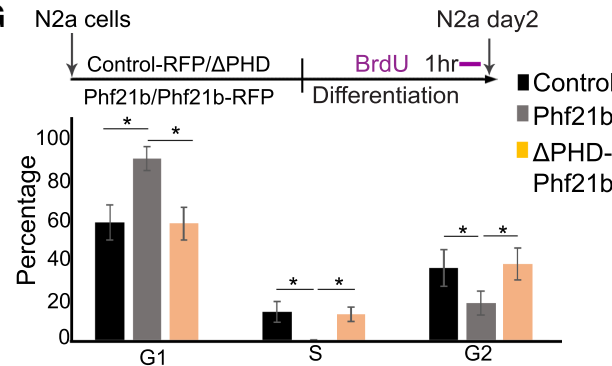

$\mathbf{F}$

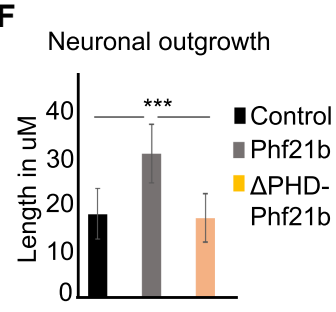

B

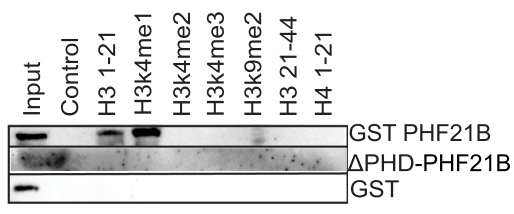

D

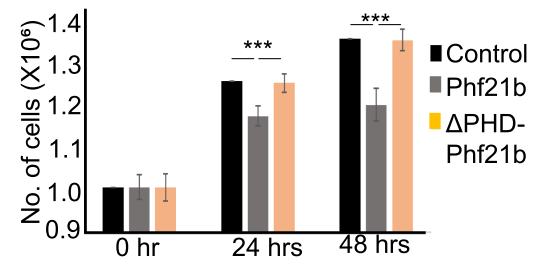

Figure 7. Phf $21 \mathrm{~b}$ exhibits strongest affinity for $\mathrm{H} 3 \mathrm{~K} 4 \mathrm{mel}$ and requires PHD for its activity. (A) Graphical representation of specificity of interaction of Phf $21 \mathrm{~b}$ with different modified histone peptides using array analysis software. $(B)$ Western blot with GST antibody after histone peptidebinding assay showing the histone binding specificity for GST protein, GST del PHD Phf21b, and GST Phf21b protein. (C) Schematic representation for the differentiation of N2a cells following transfection with different overexpression constructs. Brightfield microscopy images are shown for cells transfected with control, Phf21b, and PHD deleted Phf $21 b$ followed by their differentiation. $(D)$ Bar plot depicting the number of cells quantified after differentiation of N2a cells transfected with RFP tagged control, Phf21b, and Phf21b lacking PHD expression constructs. The cell numbers were quantified at $24 \mathrm{~h}$ and $48 \mathrm{~h}$ using an automated cell counter. Data are represented as mean \pm SD from eight biological replicates for each time point. $t$-test. $\left({ }^{* * *}\right) P<$ 0.001. (E) Immunostaining of cells from $C$ with neuronal marker Tuj1 and nuclear marker Hoechst. $(F)$ Quantification of neuronal outgrowth length of the cells in $C$ is represented. Data are represented as mean \pm SD from 10 different regions from three replicates of the different samples. $t$-test. $\left({ }^{* *}\right) P<0.001$. (G) Schematic representation and in vitro $2 \mathrm{D}$ cell cycle analysis for BrdUlabeled differentiated N2a cells transfected with RFP-tagged control, Phf21b, and Phf21b lacking PHD expression constructs as performed by FACS analysis along with the quantitation of the cells in the G1, S, and G2 phases of the cell cycle. Data are represented as mean $\pm \mathrm{SD}$ from three biological replicates for each sample. $t$-test. $\left({ }^{*}\right) P<0.05$. $(H)$ qRT-PCR showing relative expression levels of selected Phf21b target cell cycle genes following transfection of RFP tagged control, Phf21b, and Phf21b lacking PHD expression constructs in cells from $C$. Data are represented as mean $\pm \mathrm{SD}$ from three biological replicates for each samples. $t$-test. $\left({ }^{*}\right) P<0.05$.

significant decrease in their expression in Phf21b overexpressing cells, Phf21b lacking PHD failed to repress these genes (Fig. $7 \mathrm{H}$ ). Altogether, these observations suggest that Phf21b uses its PHD to repress cell cycle genes and thereby induce cell cycle exit to promote neuronal differentiation.

\section{Phf21b recruits Lsd1 and Hdac2 to generate repressive chromatin at cell cycle genes}

To decode the molecular mechanism underlying Phf21b function, we depleted Phf21b during neuronal differentiation in vitro and analyzed the recruitment of Lsd1 and Hdac2 at distinct Phf21b target cell cycle gene loci (Fig. $8 \mathrm{~A})$. Interestingly, in the absence of Phf $21 \mathrm{~b}$, Lsd1, and Hdac2 show a significant loss in the enrichment at the selected target loci (Fig. 8B). Most importantly, this was accompanied by a significant gain in $\mathrm{H} 3 \mathrm{~K} 4 \mathrm{mel}$ and $\mathrm{H} 3 \mathrm{~K} 27 \mathrm{ac}$ at the same genomic regions (Fig. 8B). This chromatin remodeling was very specific as other tested histone modification marks including $\mathrm{H} 3 \mathrm{~K} 4 \mathrm{me} 2$, H3K4me3, H3K9me2, H3K9me3, H3K9ac, H3K27me3, and H3K36me3 remained unaffected upon Phf21b knockdown (Supplemental Fig. S8). The cell cycle genes show gradually reduced levels of the active mark H3K27ac during embryonic forebrain development, further supporting that Phf21b functions to deplete this mark during this process to silence these genes (Supplemental Fig. S9a-n). These observations imply that Phf $21 \mathrm{~b}$ is induced and targeted to H3K4me1 mark present at the promoters of cell cycle genes during neuronal differentiation. Subsequently, it recruits lysine-specific demethylase Lsd 1 and histone deacetylase Hdac2 to these sites resulting in simultaneous removal of monomethylation from H3K4 as well as acetylation from $\mathrm{H} 3 \mathrm{~K} 27$. Such dual loss of active chromatin marks leads to repression of cell cycle genes, which promotes neural progenitors to exit proliferation and differentiate to neurons. 
A
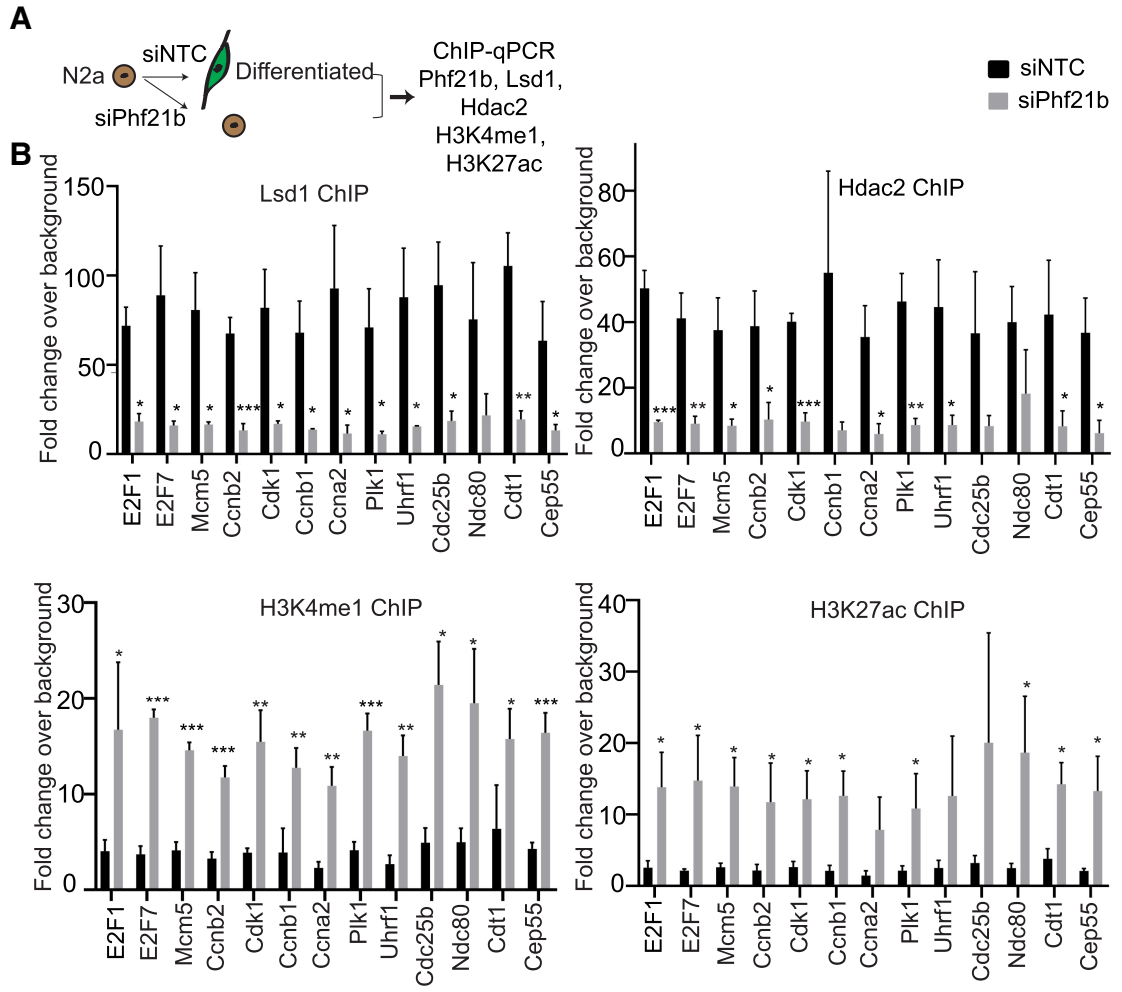

음 $407 \quad$ H3K27ac ChIP

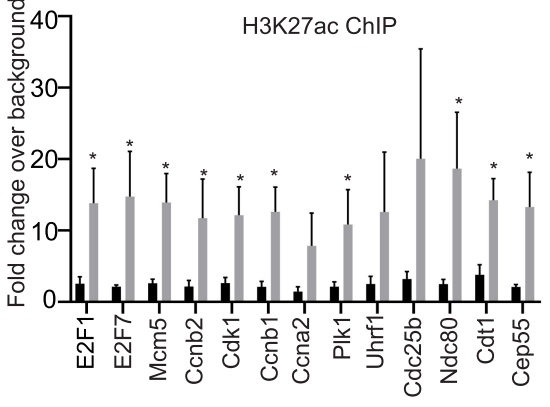

C

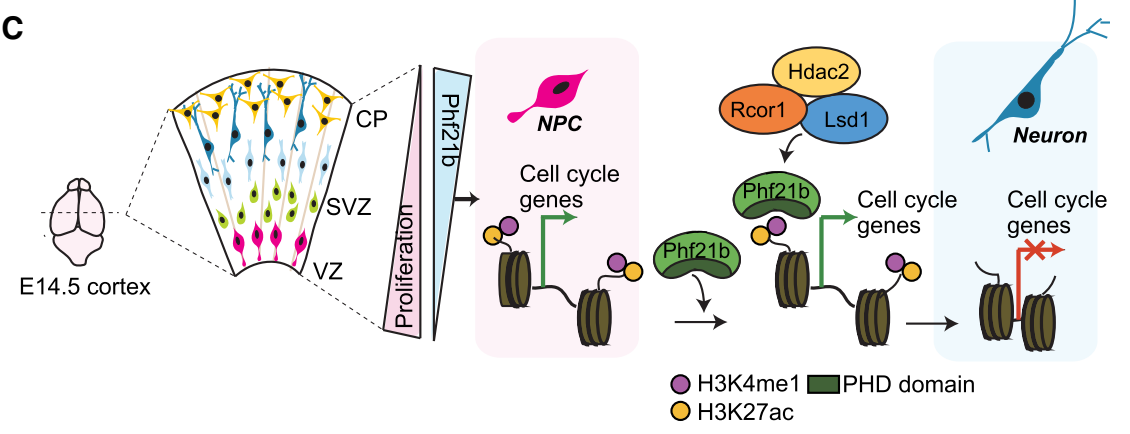

Figure 8. Phf21b recruits Lsd1 and Hdac2 to the promoters of cell cycle genes and mediates loss of $\mathrm{H} 3 \mathrm{~K} 4 \mathrm{mel}$ and $\mathrm{H} 3 \mathrm{~K} 27 \mathrm{ac}$. (A) Schematic representation of ChIP performed in differentiated $\mathrm{N} 2 \mathrm{a}$ cells with Phf21b, Lsd1, H3K4me1, and H3K27ac antibodies $(n=3)$. (B) ChIP-qPCR calculated as fold change over intergenic for the Lsd1 ChIP, Hdac2 ChIP, H3K4me1 ChIP, and $\mathrm{H} 3 \mathrm{~K} 27 \mathrm{ac}$ ChIP for promoter region of some representative cell cycle gene promoters. (C) Model summarizing proposed gene regulatory function of Phf21b on cell cycle genes during cortical development.

\section{Discussion}

The development of the mammalian cerebral cortex relies on a precisely controlled gene expression program (Guillemot et al. 2006; Spitz and Furlong 2012; Aprea et al. 2013; Itoh et al. 2013; Florio and Huttner 2014; Imayoshi and Kageyama 2014; Shibata et al. 2015; Thakurela et al. 2015; Pataskar et al. 2016; Urbán et al. 2016; Kishi and Gotoh 2018; Tsuboi et al. 2018; Zhang et al. 2019). In the developing neocortex, cells in the VZ/SVZ are largely multipotent neural stem cells and neural progenitor cells. These cells undergo self-renewal at the early stage of embryonic development to amplify the progenitor pool and subsequently differentiate into neurons. It is thus of considerable interest to uncover mechanisms controlling the switch from proliferation to differentiation during neurogenesis. Furthermore, regulation of a fine balance between proliferation and differentiation is of utmost importance to generate the cellular diversity required for proper cortical development. Despite advances, the molecular mecha- nisms controlling the switch of NSCs from proliferative to differentiative divisions to generate neurons remains poorly understood. Here we report a cortex-specific PHD finger protein, Phf $21 \mathrm{~b}$, which is up-regulated as NSCs begin to differentiate during cortical development. Our original discovery of Phf21b was based on expression analysis that was restricted to tissues representing the three lineages during development without comparison with any adult tissues. Notably, Phf $21 \mathrm{~b}$ was induced at the onset of neurogenesis and down-regulated as neurogenesis begins to cease while astrogliogenesis begins, prompting us to further investigate its function as a critical spatiotemporal regulator of neurogenesis. A deeper investigation into Phf21b expression showed that it is induced during the switch of proliferating to differentiating progenitors and then continues to be highly expressed in neurons. Our comprehensive functional analysis revealed that neurogenesis is severely compromised upon Phf21b depletion during cortical development and the Phf $21 \mathrm{~b}$ depleted cells were retained in the progenitor state. 
A combinatorial analysis of genome-wide binding data sets for Phf21b in combination with transcriptome profiling of cells lacking Phf21b during neuronal differentiation discovered that Phf21b directly binds at the promoters of critical cell cycle promoting genes for inducing transcriptional silencing during neuronal differentiation. In part, these effects can be explained by our observations that one of the direct targets of Phf21b was E2F1, which is known to be a key regulator of G1-S transition and insufficient levels of this protein are known to cause G1-S arrest (Cam and Dynlacht 2003; Bertoli et al. 2013). Phf21b depletion derepressed E2F1, thereby causing accelerated entry into the $\mathrm{S}$ phase and increased proliferation. In our analysis, the NFI motifs were found enriched at the genes down-regulated upon Phf21b depletion, which largely contains neuronal genes. The down-regulation of these genes is a secondary effect as Phf $21 \mathrm{~b}$ is a repressor. We showed previously that NFIA functions to repress neuronal genes to promote astrogliogenesis (Tiwari et al. 2018) and thus the neuronal genes, which are down-regulated upon Phf21b depletion, are potentially naturally repressed by NFIA in the later stages during cortical development to promote astrogliogenesis. Our mechanistic analysis showed that Phf $21 \mathrm{~b}$ accomplishes this function by getting recruited via $\mathrm{H} 3 \mathrm{~K} 4 \mathrm{mel}$ to cell cycle gene promoters and then targeting Hdac2 and Lsd1, which then deacetylate $\mathrm{H} 3 \mathrm{~K} 27 \mathrm{ac}$ and demethylate $\mathrm{H} 3 \mathrm{~K} 4 \mathrm{mel}$, respectively, to bring transcriptional repression. Hdac2 and Lsd1 are very established to be critical for neurogenesis (Huang and Herbert 2005; Brunmeir et al. 2009; Lim et al. 2009; Miles et al. 2015; Rusconi et al. 2017). Our findings fill a very important gap in the knowledge on their function by discovering an epigenetic reader that targets them to specific genomic loci at a critical step during corticogenesis.

Our biochemical assays revealed that $\mathrm{Phf} 21 \mathrm{~b}$ has a higher affinity for H3K4mel as compared with other histone modifications, which rely on its PHD. This result is interesting, as most of the PHD finger proteins bind $\mathrm{H} 3 \mathrm{~K} 4 \mathrm{me} 3$ while only a few proteins like Dnmt3L and BHC80 are known to bind the unmethylated state of H3K4 (Otani et al. 2009). Interestingly, as Phf21b gets recruited to cell cycle genes by docking on $\mathrm{H} 3 \mathrm{~K} 4 \mathrm{mel}$, it recruits Lsd1, which removes monomethyl from $\mathrm{H} 3 \mathrm{~K} 4$ as well as Hdac2 that deacetylates H3K27. Thus, the chromatin reading function of Phf21b has strong consequences as marked by a dual loss of two active chromatin marks $\mathrm{H} 3 \mathrm{~K} 27 \mathrm{ac}$ as well as H3K4me1, ensuring gene silencing. It is important to note that Phf 21 b only targets a subset of H3K4me1 enriched regions in the genome and future studies should investigate the mechanisms underlying its specific targeting to selected loci during neurogenesis. It remains to be investigated what decides the specificity of Phf $21 \mathrm{~b}$ targeting to specific H3K4me1 marked loci among the plethora of similar other regions available in the genome.

The above data consistently pointed to the role of Phf21b in inhibiting cell cycle progression of neural stem and progenitor cells. As a result, and given the role that a lengthening of the cell cycle is known to have toward triggering the switch from proliferation to differentiation /Calegari and Huttner 2003; Lange and Calegari
2010), Phf21b functions to promote neurogenesis. Conversely, Phf21b depletion led to faster cell cycles of neural progenitors and inhibition of their switch to neurogenesis. Further supporting these findings, Phf21b overexpression led to an increased number of electroporated cells in upper cortical layers presumably resulting from an accelerated cell cycle exit and premature neuronal differentiation. The loss of Phf $21 \mathrm{~b}$ during neurogenesis also led to increased levels of phosphorylated Retinoblastoma, supporting increased cell proliferation. This was in line with a previous study in which overexpression of Cdk4/ Ccnd1 was used to shorten the cell cycle during corticogenesis and found to have an effect specifically in basal, but not apical, progenitors (Nonaka-Kinoshita et al. 2013). In turn, these results place Phf $21 \mathrm{~b}$ as a master cell cycle regulator during neurogenic commitment.

Recent years have witnessed strong evidence that several complex diseases including neurological disorders involve aberrations in epigenetic gene regulatory programs (Urdinguio et al. 2009; Jakovcevski and Akbarian 2012; Rubeis et al. 2014; Coe et al. 2019). As mutations at the PHF21B locus were recently linked to the major depressive disorder (MDD) and Phelan-McDermid syndrome in humans (Sarasua et al. 2014; Wong et al. 2017), future work should involve functional analysis to decode the molecular mechanisms of how PHF21b dysfunction may contribute to the etiology of these disorders. Interestingly, the onset of depression has previously been associated with the relationship between cell cycle regulation and neurogenesis (Malberg et al. 2000; Czéh et al. 2001; Cunningham et al. 2009; Jakovcevski and Akbarian 2012; Shohayeb et al. 2018; Teo et al. 2018). Furthermore, aberrations in epigenome have also been linked with depression (Tsankova et al. 2007; Sun 2012; Menke and Binder 2014; Nestler 2014). It is likely that additional insights into the misregulation of Phf21b function in neurological disorders will fill an important gap in understanding the etiology of these disorders and eventually pave the way for better therapeutic avenues.

\section{Materials and methods}

Reagent, antibodies, cell lines, and oligos

Lists of the reagents, antibodies, cell lines, and oligos used in this study are in the Supplemental Material.

\section{Screening for PHD-containing proteins in the brain}

We looked at the Interpro database under the domain category IPR001965 (zinc finger, PHD type) (Hunter et al. 2009). We then investigated the tissue-specific expression pattern of those 75 proteins in embryonic tissues using publicly available RNA-seq data from various sources (GSE38805, GSE49847, GSM723775, GSM929710, and GSE40823). Among the 75 proteins, 27 were found to have a brain-specific expression pattern.

\section{Cell culture}

Murine Neuro2a cells (N2a cells) were cultured at $37^{\circ} \mathrm{C}$ in $7 \% \mathrm{CO}_{2}$ and $88 \%$ relative humidity in $10 \mathrm{~mL}$ of DMEM supplemented 
with $10 \%$ fetal calf serum, $1 \times$ NEAA, and $2 \mathrm{mM}$ L-glutamine. Neuronal differentiation in N2A cells was induced by adding 20 $\mu \mathrm{M}$ retinoic acid in DMEM supplemented with $2 \%$ FBS, $1 \%$ glutamine, and $1 \%$ NEAA. For ES cell experiments, ES159 cells on feeders were split every $2 \mathrm{~d}$ onto tissue culture dishes coated with $0.2 \%$ gelatin, and the medium was changed daily. All ES cell experiments were performed at the feeder-free five stages. In vitro neuronal differentiation was performed as described by Bibel et al. (2004, 2007), where ES cells were directly plated onto PORN/Laminincoated tissue culture dishes and cultivated for $2 \mathrm{~d}$ in N2 medium followed by complete medium for induced neuron (iTN) formation. For ES cell ChIP and RNA seq, transgenic A2lox ES cells harboring the murine Phf21b were fused to an $\mathrm{N}$-terminal HA tag under the control of a doxycycline-inducible promoter generated according to Iacovino et al. (2014). Ectopic induction of Phf21b was achieved with $500 \mathrm{ng} / \mathrm{mL}$ doxycycline for $24 \mathrm{~h}$.

\section{Animals}

Mice were kept on a regular 12-h light /12-h dark cycle. Timed pregnant C57BL/6 mice were purchased from commercial suppliers. The day the plug was detected was considered day 0 . The handling of the mice and the experimental procedures were conducted in accordance with European, national, and institutional guidelines for animal care.

\section{Western blotting}

For endogenous Phf21b expression check, the cortex was dissected from E11.5, E13.5, E14.5, E15.5, E16.5, and E18.5 mouse brains and lysed using RIPA buffer containing $50 \mathrm{mM}$ Tris (pH 8), $1 \%$ NP40, $0.5 \%$ sodium deoxycholate, $0.1 \%$ SDS, $150 \mathrm{mM} \mathrm{NaCl}$, $5 \mathrm{mM}$ EDTA, $1 \%$ glycerol, $2.5 \mathrm{mM} \mathrm{MgCl}_{2}$, and $2 \mathrm{mM}$ sodium orthovanadate. After quantifying with Bradford reagent, $40 \mu \mathrm{g}$ of lysates from each time points was loaded to an SDS gel. After transfer, the PVDF membrane was blocked with 5\% nonfat milk and incubated overnight at $4^{\circ} \mathrm{C}$ with 1:1000 dilution Phf21b antibody (Sigma). The next day, the blot was incubated with 1:5000 diluted HRP0conjugated secondary antibody for $1 \mathrm{~h}$ and developed.

\section{In utero electroporation (IUE)}

To obtain endotoxin-free transfection-grade plasmids, the plasmids were purified using the Qiagen EndoFree plasmid maxi kit according to the manufacturer's protocol. Purified plasmids were handled carefully to avoid pathogenic contamination. For knockdown studies, shRNA specific for Phf21b (sequence in the Supplemental Material) was cloned into the pSUPER Neo GFP vector. For control, a scrambled nontargeting control (NTC) was cloned into the pSUPER Neo GFP vector. Overexpression constructs were prepared by cloning a Phf $21 b$ shRNA-resistant gene into the pIRES-RFP vector containing IRES-RFP (Phf21bIRES-RFP). The original pIRES-RFP backbone was used as a control-IRES-RFP plasmid. Rescue experiment was performed by injection of equimolar ratios of shRNA and shRNA-resistant overexpression constructs.

The in utero electroporation experiments were carried out as described (Baumgart and Grebe 2015). Timed pregnant mice were anesthetized with isoflurane (induction chamber: $2.8 \%$, surgery via mask: $2.5 \%$ ). After fixation of the limbs, the surgical area was sterilized using $70 \%$ ethanol. The mother was then covered with sterile gauze only exposing the surgical area. The gauze was moistened with a physiological saline solution containing the bacteriostatic agent benzyl alcohol as a $0.9 \%$ solution. Subse- quently, the abdominal cavity was cut open (skin incision: 1.5-2 $\mathrm{cm}$, muscle incision: $11.5 \mathrm{~cm}$ ) and the uterine horns were carefully extracted using ring forceps. The abdominal cavity and especially the exposed uterine horns were kept moist with warmed $0.9 \%$ benzyl alcohol solution throughout the surgery. Specially designed glass capillaries were used for injection of the DNA solution. Borosilicate glass capillaries $(0.8-0.9 \mathrm{~mm}$ diameter, World Precision Instrument, Inc.) were pulled using a P-97 micropipette puller (Sutter Instrument Company). The tips were inclined at $35^{\circ}$ angles (Microgrinder EG-44, Narishige). Maximum outer tip diameter was kept to $60 \mu \mathrm{m}$, defined volumes were drawn up into the capillary, and the capillary length per microliter was calculated. The DNA solution was colored by adding $1 \mu \mathrm{L}$ of Fast Green solution (0.01 g/15 mL TE; Carl Roth) per $10 \mu \mathrm{L}$ of DNA solution so that successful injection could be verified visually. One microliter of colored DNA solution containing 3-4 $\mu \mathrm{g}$ of the desired plasmid was injected into the lateral ventricle. The injection volume was kept low to reduce the spreading to all parts of the other ventricles and thereby enhance the specificity. The application of the DNA solution was performed slowly $(1 \mu \mathrm{L}$ in $10-20 \mathrm{sec}$ ) with an injection depth of $0.5 \mathrm{~mm}$. Appropriate voltage was applied via specialized platinum electrodes (Nepagene CUY 650P, interval cycle length $50 \mathrm{msec}$, interval pause $950 \mathrm{msec}$ ). The voltage was supplied from electroporator Nepagene CUY 21 and the size of the electroporation paddle was adapted to the embryonic stage $(3 \mathrm{~mm})$.

After electroporation, the uterine horns were replaced in their original position in the abdominal cavity. The muscles and skin of the surgical wound were separately carefully sutured with sterile 5-0 Perma-Hand silk suture (Ethicon K890H Johnson\&Johnson). Subsequently, the mice were analogized subcutaneously with Carprofen ( $4 \mathrm{mg} / \mathrm{kg}$ bodyweight, $24 \mathrm{~h}$ depot, Rimadyl, Pfizer) and, if necessary, followed for an additional 1-2 d.

\section{Surgery tools}

The following instruments were used performing the surgery: ring forceps $(1 \mathrm{~mm} \mathrm{ID} / 1.5 \mathrm{~mm} \mathrm{OD}, 4.8 \mathrm{~mm} \mathrm{ID} / 6 \mathrm{~mm} \mathrm{OD}$, and $2.2 \mathrm{~mm} \mathrm{ID} / 3 \mathrm{~mm} \mathrm{OD}$ ), Adson forceps (serrated straight, $12 \mathrm{~cm}$ ); iris scissors (delicate straight-sharp/Blunt,10 cm), Mayo-Stille scissors (straight, $15 \mathrm{~cm}$ ), Dumont \#5 forceps, Inox, and Castroviejo needle holder (with lock, tungsten carbide, $14 \mathrm{~cm}$ ). The instruments were sterilized using an FST 250 Hot Bead sterilizer. All instruments were purchased from Fine Science Tools.

\section{Immunofluorescence assay}

IUE and wild-type samples For endogenous Phf21b stainings, E14.5 mouse embryonic brains were used. For IUE samples, E17.5 stage embryonic brains were used. The whole brain was fixed overnight at $4^{\circ} \mathrm{C}$ in $4 \%$ PFA in PBS followed by cryoprotection in $10 \%$ sucrose for $2 \mathrm{~h}$, followed by $30 \%$ sucrose overnight. Brains samples were embedded in Tissue-Tek and stored at $20^{\circ} \mathrm{C}$ followed by cryosectioning into 12 - $\mathrm{um}$ sections using Leica Cryotome. Samples were preblocked with $2 \%$ BSA and $0.5 \%$ Triton X-100 (in PBS) for $1 \mathrm{~h}$. Subsequently, the samples were incubated with sample-specific primary antibodies (1:200 diluted Phf21b [Sigma], 1:400 Ctip2 [Abcam], 1:400 GFP [2Bscientific], 1:400 RFP [Chromotek], 1:400 Tbr2 [Abcam], and 1:400 Tbr1 [Abcam]) overnight at $4^{\circ} \mathrm{C}$ followed by three washes with PBS and incubated with florescent-labeled secondary antibody for $1 \mathrm{~h}$ at room temperature. The samples were counterstained with 1:500 diluted Hoechst, mounted with Immu-Mount, and imaged with a Leica TCS SP5 confocal microscope. The images were processed with ImageJ software, and distribution of the 
electroporated cells was calculated after binning into three cortical layers.

siRNA-based knockdown

For all siRNA-mediated knockdown experiments, undifferentiated N2a cells were seeded and predepleted for $2 \mathrm{~d}$ by transfecting with ON-TARGETplus SMARTpool siRNAs (i.e., a mixture of four siRNAs provided as a single reagent from Dharmacon) every second day. For siRNA transfections, Lipofectamine RNAiMax was used according to the manufacturer's instructions. For N2a differentiation, 2-d predepleted undifferentiated cells were differentiated by adding retinoic acid along with siRNAs for $2 \mathrm{~d}$ in N2a differentiation medium before harvesting.

Florescence-activated cell sorting

FACS of cortical cells were performed as described previously. In brief, E17.5 wild-type or electroporated cortices were dissociated using the papain-based neural dissociation kit (Milteney Biotec); after removal of meninges and ganglionic eminences, FACS was performed with a gating strategy for green $(488 \mathrm{~nm})$ fluorescence. The sorted cells were immediately used for RNA extraction followed by RNA-seq.

\section{RNA isolation and quantitative RT-PCR}

Total RNA was prepared using TRIzol reagent (Invitrogen) and reverse-transcribed with a first strand cDNA synthesis kit (Fermentas). The RNA of FAC-sorted cortical cells was extracted using the RNeasy micro kit (Qiagen) and reverse-transcribed with the SuperScript VILO cDNA synthesis kit (Invitrogen). The transcripts were quantified by qPCR using SYBR Green PCR Master mix (ABI) on a ViiATM 7 real-time PCR system (Life Technologies). Mouse TBP or Rpl19 primers were used for normalization of RNA expression. The sequences of all of the primers used in this study are in the Supplemental Material.

\section{RNA-seq analysis}

For the in vivo samples, Nugen Ovation SoLo RNA-seq kit was used to prepare a library according to the manufacturer's protocol. For the in vitro samples, poly(A) library was generated according to Illumina's protocol. Samples were sequenced in Illumina HiSeq 2500 or Illumina NextSeq 500 to obtain 25 million reads each. After a quality check of FastQ files using FastQC v2.6.14, the raw sequencing reads were aligned to the mouse reference genome (mm9) with UCSC's annotations using TopHat v2.0.8 (Trapnell et al. 2009). SAMTools v0.1.19 (Li et al. 2009) was used to convert the BAM output to SAM format and to sort the BAM file. From the aligned BAM files, the read counts per gene were calculated using the HTSeq program v0.5.4p1. Differential expression (DE) analysis of in vivo samples was performed by EdgeR package (Robinson et al. 2010), which provided normalized read counts and performed statistical tests. The genes with a $P$ value $<0.05$ and absolute fold change $>1.5$-fold were considered as DEGs. DE analysis of in vitro samples was done by DESeq package (Anders and Huber 2010), which generated normalized read counts and performed statistical tests. The genes with FDR $<0.05$ and absolute fold change $>1.5$-fold were considered as significant differentially expressed genes (DEGs). GO term enrichment analysis was performed using DAVID software (Huang et al. 2009) with the enrichment criteria of $P$-values $<0.05$ and gene counts more than five. For the motif enrichment analysis of DEGs, promoter regions upstream of the DEGs were used by for analysis using HOMER v4.7 (Heinz et al. 2010).

Functional analysis in N2a cells with overexpression constructs

For preparation of cells with various constructs, N2a cells were seeded at 1 million cells per $10-\mathrm{cm}$ dish and transfected with RFP-tagged control, $\triangle \mathrm{PHD}$ Phf $21 \mathrm{~b}$ overexpression, and Phf $21 \mathrm{~b}$ overexpression plasmids. After $48 \mathrm{~h}$ of transfection, the cells were harvested and seeded in N2a differentiation medium with retinoic acid using a density of 1 million cells per $10-\mathrm{cm}$ dish for $48 \mathrm{~h}$. Cell number was quantified using an automated cell counter. For immunofluorescence and bright-field images, cells were grown on coverslips, and for immunostaining, cells were stained with neuronal marker Tuj1 and the nuclear marker Hoechst. For RT-qPCR analysis, RNA was isolated from the samples using Trizol followed by cDNA synthesis, and quantitative PCR was performed using primers against select Phf $21 \mathrm{~b}$ target cell cycle genes. Cell cycle gene expression was represented as relative expression to Gapdh.

\section{Cell cycle analysis}

For in vivo cell cycle analysis, IUEs with knockdown construct were performed at E13.5 embryos. Three hours and $9 \mathrm{~h}$ before sacrifice at E15.5, the mouse was injected with BrdU intraperitoneally. Alternately, $4 \mathrm{~h}$ before sacrifice, EdU was injected intraperitoneally. The brains were fixed in PFA followed by $30 \%$ sucrose cryoprotection overnight. Leica cryotome was used to make $12-\mu \mathrm{m}$ sections. For stainings, antigen retrieval was done by boiling the samples in a water bath at $70^{\circ} \mathrm{C}$ with 1:10 diluted solution of $1 \mathrm{M}$ sodium citrate. The sample was cooled for $20 \mathrm{~min}$ to room temperature followed by three PBS washes, $20 \mathrm{~min}$ in $0.5 \%$ Triton X-100, and $30 \mathrm{~min}$ in $0.1 \mathrm{M}$ glycine. The samples were then blocked with $2 \%$ BSA and $0.5 \%$ Triton X-100 (in PBS) for $1 \mathrm{~h}$. GFP (diluted 1:400; 2Bscientific), PH3 (diluted 1:200; Abcam); and Tbr2 (diluted 1:200; Abcam) primary antibodies were added overnight at $4^{\circ} \mathrm{C}$. The next day, fluorescent-conjugated secondary antibodies were added after three washes with PBS. This was followed by three washes in PBS with $0.05 \%$ Triton and $30 \mathrm{~min}$ in PFA $4 \%$. The samples were washed three times with PBS and incubated for $25 \mathrm{~min}$ at $37^{\circ} \mathrm{C}$ in $2 \mathrm{M} \mathrm{HCl}$. After incubation, samples were washed three times with PBS incubated for $20 \mathrm{~min}$ at room temperature with $0.1 \mathrm{M}$ glycine, washed once with PBS, and finally blocked with $2 \%$ BSA and $0.5 \%$ Triton X-100 (in PBS) for $1 \mathrm{~h}$. BrdU/EdU antibody (diluted 1:300) was incubated overnight with the samples followed by secondary antibody incubation for $1 \mathrm{~h}$ at room temperature. Finally, samples were stained with Hoechst, mounted using Immu-Mount, and imaged with a Leica TCS SP5 confocal microscope at 20x. The images were processed with ImageJ software and the number of cells with GFP, BrdU, EdU, Tbr2, and PH3 was counted to get the mitotic index.

For in vitro cell cycle analysis, the undifferentiated N2a cells were transfected with RFP-tagged overexpressing control, PHD0deleted Phf21b, or Phf21b constructs for $48 \mathrm{~h}$ followed by differentiation for $2 \mathrm{~d}$. The differentiated N2a cells were pulsed with $10 \mu \mathrm{M}$ BrdU for $1 \mathrm{~h}$ and washed thoroughly with medium. The cells were then dissociated with trypsin and fixed for 15 min at room temperature using Cytofix/Cytoperm buffer (BD Biosciences). After two washes with Perm/Wash buffer (BD Biosciences), the differentiated N2a cells were permeabilized with Cytoperm permeabilization buffer (BD Biosciences) for $10 \mathrm{~min}$ at $4^{\circ} \mathrm{C}$, washed with Perm/Wash buffer (BD Biosciences), and subjected to DNase $\left(300 \mu \mathrm{g} / \mathrm{mL}\right.$ in PBS) digestion for $1 \mathrm{~h}$ at $37^{\circ} \mathrm{C}$. The 
staining with FITC-BrdU antibody was performed using the BrdU flow kit (BD Biosciences) for $20 \mathrm{~min}$ at room temperature. DNA was counterstained with Hoechst along with 30-min RNase 10.1 $\mathrm{mg} / \mathrm{mL}$ final concentration) digest. Samples were subsequently measured using the BD LSRFortessa cell analyzer with BD FACSDiva software, and plots were generated using FlowJo. Percentages of differentiated N2a cells among different phases of the cell cycle such as G1, S, and G2 were determined and plotted.

\section{Immunoprecipitation}

For in vivo IP, E14.5 cortex was dissected and homogenized in JS buffer for $30 \mathrm{~min}$ at $4^{\circ} \mathrm{C}$. The lysate was sonicated for five rounds (30 sec on/ $30 \mathrm{sec}$ off, high energy) with a Bioruptor Plus (Diagenode) at $4^{\circ} \mathrm{C}$ and cleared by centrifugation with $16,000 \mathrm{~g}$ for 15 min at $4^{\circ} \mathrm{C}$ afterward. Two milligrams of total protein proceeded for IP after $5 \%$ input was taken and incubated with $5 \mu \mathrm{g}$ of endogenous Phf $21 \mathrm{~b}$ antibody was used for IP. The remaining protocol was the same as above. A 1:1000 dilution of Lsdl antibody (Abcam), Hdac2 antibody (Abcam), and Phf21b antibody (Sigma) was used to probe the blot for validating the interaction. Two sets of replicates were processed for IP-mass spectrometry.

For in vitro IP, undifferentiated N2a cells were transiently transfected with plasmids encoding HA-Flag-tagged Phf21b using Lipofectamine 2000. The control and Phf21b transfected N2a cells were labeled by SILAC-based methods using media labeled with heavy or light arginine and lysine. After $48 \mathrm{~h}$ of transfection, the N2a cells were lysed in JS lysis buffer $(50 \mathrm{mM}$ HEPES at $\mathrm{pH}$ $7.5,150 \mathrm{mM} \mathrm{NaCl}, 5 \mathrm{mM}$ EGTA, $1.5 \mathrm{mM} \mathrm{MgCl} 2,1 \%$ glycerol, $1 \%$ Triton X-100 supplemented with protease inhibitors) for $30 \mathrm{~min}$ at $4^{\circ} \mathrm{C}$. The lysate was sonicated for five rounds $(30 \mathrm{sec}$ on/ $30 \mathrm{sec}$ off, high energy) with a Bioruptor Plus (Diagenode) at $4^{\circ} \mathrm{C}$ and cleared by centrifugation with $16,000 \mathrm{~g}$ for $15 \mathrm{~min}$ at $4^{\circ} \mathrm{C}$ afterward. Two micrograms of total protein proceeded for IP after $5 \%$ input was taken and incubated with $5 \mu \mathrm{g}$ of Flag antibody overnight. The immunocomplex was precipitated for $3 \mathrm{~h}$ with Protein $\mathrm{G}$ beads, and the beads were then washed twice with $1 \mathrm{~mL}$ of NET buffer $(50 \mathrm{mM}$ Tris- $\mathrm{HCl}$ at $\mathrm{pH} 7.5,150 \mathrm{mM}$ $\mathrm{NaCl}, 5 \mathrm{mM}$ EDTA, $0.1 \%$ Triton X-100 supplemented with protease inhibitors) followed by centrifugation at $2000 \mathrm{~g}$ for $1 \mathrm{~min}$ at $4^{\circ} \mathrm{C}$. The beads were incubated with $40 \mu \mathrm{L}$ of $1 \times$ LDS sample buffer and boiled while shaking at $600 \mathrm{rpm}$ for $10 \mathrm{~min}$ at $50^{\circ} \mathrm{C}$ for elution. The supernatant was saved after centrifugation with $4000 \mathrm{~g}$ for $2 \mathrm{~min}$ at room temperature, the elution was repeated with $40 \mu \mathrm{L}$ of $1 \times$ LDS sample buffer, and the supernatants were combined. For Western blot analysis, the input was supplemented with $1 \times$ LDS sample buffer and along with the IP elution fraction supplemented with $100 \mathrm{mM} \mathrm{DTT}$, boiled for $5 \mathrm{~min}$ at $90^{\circ} \mathrm{C}$, and directly used for SDS-PAGE. A 1:1000 dilution of Lsd1 antibody (Abcam), HDAC2 antibody (Abcam), and Phf21b antibody (Sigma) was used to probe the blot for validating the interaction.

Mass spectrometry analysis

Peptide fractions were analyzed using a quadrupole Orbitrap mass spectrometer (Q Exactive Plus, Thermo Scientific) equipped with a UHPLC system (EASY-LLC 1000, Thermo Scientific). Peptide samples were loaded onto C18 reversed-phase columns and eluted for $2 \mathrm{~h}$ with a linear gradient of acetonitrile from $8 \%$ to $40 \%$ containing $0.1 \%$ formic acid. The mass spectrometer was operated in data-dependent mode with automatic switching between MS and MS2 acquisition. Survey full-scan MS spectra $(\mathrm{m} / \mathrm{z}$ 300-1650) were acquired in the Orbitrap. The 10 most intense ions were sequentially isolated and fragmented by higherenergy C-trap dissociation (HCD) 64. Peptides with unassigned charge states or charge state less than +2 were excluded from fragmentation. The fragment spectra were acquired in the Orbitrap mass analyzer. From the in vivo IP-mass spectrometry, 88 interactors were identified with the enrichment cutoff twofold above IgG control from both forward and reverse experiments reproducibly. Using CRAPome information, putative false positive interactors were excluded and 66 proteins were identified as putative interactors. Protein-protein interaction (PPI) networks between those putative binding partners were obtained using the STRING database (Mering et al. 2005) with experimental evidence and interaction score $>0.4$. The PPI network was visualized using Cytoscape software.

\section{Chromatin immunoprecipitation (ChIP) assay}

The differentiated N2a cells were cross-linked in medium containing $1 \%$ formaldehyde for $10 \mathrm{~min}$ at room temperature and then neutralized with $0.125 \mathrm{M}$ glycine, scraped off, and rinsed twice with $10 \mathrm{~mL}$ of cold $1 \times$ PBS. The differentiated N2a cells were centrifugated at $600 \mathrm{~g}$ for $7 \mathrm{~min}$ at $4^{\circ} \mathrm{C}$. The pellets were resuspended in $10 \mathrm{~mL}$ of buffer L1 $(50 \mathrm{mM}$ HEPES KOH at $\mathrm{pH} 7.5$, $140 \mathrm{mM} \mathrm{NaCl}, 1 \mathrm{mM}$ EDTA at pH 8.0, 10\% glycerol, 5\% NP-40, $0.25 \%$ Triton $\mathrm{X}-100$ ) and incubated for $10 \mathrm{~min}$ at $4{ }^{\circ} \mathrm{C}$, followed by centrifugation at $1300 \mathrm{~g}$ for $5 \mathrm{~min}$ at $4^{\circ} \mathrm{C}$. The pellet was then resuspended in $10 \mathrm{~mL}$ of buffer L2 $(200 \mathrm{mM} \mathrm{NaCl}, 1 \mathrm{mM}$ EDTA at $\mathrm{pH} 8.0,0.5 \mathrm{mM}$ EGTA at $\mathrm{pH} 8.0,10 \mathrm{mM}$ Tris at $\mathrm{pH} 8.0$ ) and incubated for $10 \mathrm{~min}$ at room temperature, followed by centrifugation at $1300 \mathrm{~g}$ for $5 \mathrm{~min}$ at $4^{\circ} \mathrm{C}$. The pellet was resuspended in the desired amount of buffer L3 (1 mM EDTA at pH 8.0, $0.5 \mathrm{mM}$ EGTA at pH 8.0, $10 \mathrm{mM}$ Tris at $\mathrm{pH} 8.0,100 \mathrm{mM} \mathrm{NaCl}, 0.1 \%$ sodium deoxycholate, $0.17 \mathrm{mM}$ N-lauryl sarcosine) containing protease inhibitors, sonicated using a Bioruptor Plus (Diagenode), and incubated overnight at $4^{\circ} \mathrm{C}$. The cellular debris was removed by spinning at $14,000 \mathrm{~g}$ for $10 \mathrm{~min}$ at $4^{\circ} \mathrm{C}$ and chromatin was quantitated. Subsequently, 60 or $25 \mu \mathrm{g}$ of chromatin was precleared with $40 \mu \mathrm{L}$ of agarose beads and incubated overnight at $4^{\circ} \mathrm{C}$

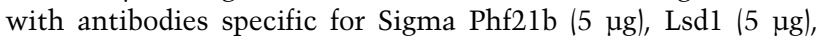
Hdac2 $(5 \mu \mathrm{g})$, or various histone modification antibodies $(2 \mu \mathrm{g})$, respectively. The next day, $40 \mu \mathrm{L}$ of protein $\mathrm{A} / \mathrm{G}$ agarose beads that had been preblocked with tRNA and BSA for $3 \mathrm{~h}$ at $4^{\circ} \mathrm{C}$ was added. After incubation, the beads were washed twice with $1 \mathrm{~mL}$ of buffer L3, once with $1 \mathrm{~mL}$ of DOC buffer (10 mM Tris at $\mathrm{pH}$ 8.0, 0.25 $\mathrm{M} \mathrm{LiCl}, 0.5 \%$ NP-40, 0.5\% Na-deoxycholate, $1 \mathrm{mM}$ EDTA), and the bound chromatin was eluted in $1 \%$ SDS/0.1 M NaHCO3. The supernatant was treated with $0.2 \mathrm{mg} / \mathrm{mL}$ RNase A for $30 \mathrm{~min}$ at $37^{\circ} \mathrm{C}$ followed by treatment with $50 \mu \mathrm{g} / \mathrm{mL}$ proteinase $\mathrm{K}$ for 2.5 $\mathrm{h}$ at $55^{\circ} \mathrm{C}$. The cross-linking was performed overnight at $65^{\circ} \mathrm{C}$ with gentle shaking. The DNA was purified by phenol-chloroform extraction, followed by ethanol precipitation and finally resuspended in $40 \mu \mathrm{L}$ of TE buffer. The ChIP samples were submitted for sequencing in the Institute of Molecular Biology Core Facility to obtain $\sim 25$ million to 30 million reads for each sample.

For ChIP validations, qPCR was done using $1 \mu \mathrm{L}$ of the ChIP material to set up qPCR using SYBR Green PCR Master mix (ABI) on a ViiATM 7 real-time PCR system (Life Technologies). Primers amplifying an intergenic region were used for normalization of ChIP enrichment above background. The sequences of all primers used in this study are in the Supplemental Material.

\section{ChIP-seq analysis}

ChIP-seq libraries were prepared according to the manufacturer's instructions from Illumina followed by next-generation sequencing. Quality control of the ChIP sequencing output files was 
performed using FastQC v2.6.14. Sequencing reads were aligned to the mouse reference genome (mm) using Bowtie v0.12.9 (Langmead 2010) and each read was aligned to maximally one position in the genome. SAMTools v0.1.19 (Li et al. 2009) was used to convert the SAM file into BAM format and to sort and index the BAM file. Sorted BAM files were used for peak calling using MACS2 v2.0.10 (Zhang et al. 2008) with default parameters. For the UCSC genome browser track visualization, WIG files were obtained using the QuasR package (Gaidatzis et al. 2015). The raw read counts that aligned to each peak region and enrichment score above the input were calculated using QuasR. For the publicly available Lsd1 ChIP-seq (GSE75039) of mouse embryonic cortex and H3K27ac ChIP-seq (ENCODE) of mouse embryonic forebrain, FastQ files were downloaded and processed with the same pipeline used for the Phf21b ChIP-seq. Motif enrichment analysis was performed using HOMER v4.7 with the BED files containing the significantly enriched peak locus.

\section{ATAC-seq}

ATAC-seq was performed as described previously (Buenrostro et al. 2013). A total of 50,000 undifferentiated or differentiated $\mathrm{N} 2 \mathrm{a}$ cells was collected and lysed in $50 \mu \mathrm{L}$ of lysis buffer containing $10 \mathrm{mM}$ Tris- $\mathrm{HCl}$ (pH 7.4), $10 \mathrm{mM} \mathrm{NaCl}, 3 \mathrm{mM} \mathrm{MgCl}$, and $0.2 \%(\mathrm{v} / \mathrm{v})$ Igepal CA-630. The nuclei were centrifuged at $500 \mathrm{~g}$ for $10 \mathrm{~min}$ at $4^{\circ} \mathrm{C}$. This was followed by transposition reaction using Nextera DNA sample preparation kit for $30 \mathrm{~min}$ at $37^{\circ} \mathrm{C}$ and purification by Qiagen PCR minielute kit. Library preparation was done using NEB Next High-Fidelity $2 \times$ PCR Master Mix for 10-12 cycles and PCR-purified. Size selection of the library was done using AMPure beads followed by a Agilent Bioanalyzer run and quantitation by qPCR using the KAPA library quantification kit. Libraries were sequenced with the Illumina NextSeq system to generate 30 million single-end reads.

\section{ATAC-seq analysis}

Quality control of the ATAC sequencing output was performed using FastQC v2.6.14. Raw sequencing reads were aligned to the mouse reference genome $(\mathrm{mm} 9)$ using Bowtie v0.12.9 to convert the SAM file into BAM format and to sort and index the BAM file. From the sorted BAM file, peak calling was performed using MACS2 v2.0.10 with BAMPE option. Generation of WIG files and calculation of enrichment scores above input for each of the peaks were performed using QuasR (Gaidatzis et al. 2015). DE analysis of enrichment was performed using DESeq (Anders and Huber 2010) with the criteria of $P$-value $<0.1$.

\section{Protein purification from insect cell lines}

The full-length Phf21b, del PHD Phf21b, and PHD-only domains were cloned into vector pCoofy28 with His6-GST tag and subsequently recombined to a bacmid as described previously (Scholz et al. 2013). Protein purification was done at the Institute of Molecular Biology Core Facility according to the Bac-to-Bac expression system from Invitrogen. Briefly, SF9 insect cells were transfected with the recombinant bacmid and cells were grown to produce recombinant baculovirus for $3 \mathrm{~d}$. The supernatant containing the baculovirus was collected and amplified and titer was determined before infecting the High Five insect cells for $3 \mathrm{~d}$. The cells were harvested and lysed in lysis buffer containing $50 \mathrm{mM}$ Hepes (pH 8.0), $200 \mathrm{mM} \mathrm{NaCl}, 5 \%$ glycerol, and $10 \mathrm{mM} \beta$-mercaptoethanol. The lysate was sonicated for four cycles with $30 \mathrm{sec}$ on/off and spun at 15,000 $\mathrm{g}$ for $40 \mathrm{~min}$. The supernatant was filtered through a $0.45-\mu \mathrm{m}$ sterile filter, loaded onto a GST column, and eluted with $20 \mu \mathrm{M}$ glutathione. FPLC was done in Äkta Prime-1 and desired fractions were collected. Samples were further processed using a heparin column followed by concentration using $10-\mathrm{kDa}$ concentrator to get rid of larger impurities. The purified proteins were quantified using Bradford reagent and stored at $-80^{\circ} \mathrm{C}$.

\section{Peptide array and analysis}

The peptide array containing 384 histone peptides containing 59 posttranslation modifications in duplicates was analyzed to determine the binding specificity of histone-interacting domains. The peptide array used was modified histone peptide array from Active Motif (13001). The peptide array was blocked in 5\% nonfat milk followed by incubation with $25 \mu \mathrm{M}$ GST-tagged purified protein overnight at $4^{\circ} \mathrm{C}$ in binding buffer containing $50 \mathrm{mM}$ HEPES ( $\mathrm{pH} 7.5$ ), $300 \mathrm{mM} \mathrm{NaCl}, 20 \%$ fetal bovine serum (FBS), and $0.1 \%$ NP-40. This was followed by washing three times in $1 \times$ TBST (10 mM Tris at $\mathrm{pH} 8.0,150 \mathrm{mM} \mathrm{NaCl}, 0.1 \%$ Tween 20). The array was incubated with GST antibody for $2 \mathrm{~h}$, followed by washing with TBST. The array was developed with $5 \mathrm{~mL}$ of SuperSignal West Pico chemiluminescent substrate (Thermo Scientific) for $5 \mathrm{~min}$ and images were acquired with an Alpha imager. The analysis was done using Array Analyze software from Active Motif, which determines the cutoff and specificity automatically based on background and signal level.

\section{In vitro peptide pull-down assay}

Two micrograms of GST-tagged purified protein or GST protein alone was incubated with $0.5 \mu \mathrm{g}$ of biotinylated histone peptides overnight at $4^{\circ} \mathrm{C}$ in binding buffer $(20 \mathrm{mM}$ Tris- $\mathrm{HCl}$ at $\mathrm{pH} 7.5,150$ $\mathrm{mM} \mathrm{NaCl}, 0.1 \%$ Triton X-100). The peptides were pulled down with streptavidin beads after a 2 -h incubation, washed three times with binding buffer, and then eluted with $1 \times$ SDS loading buffer. Western blotting was performed along with $5 \%$ input and probed with GST antibody $(1: 1000)$ to detect the interacting protein.

Quantification and statistical analysis

All data are represented as mean $\pm \mathrm{SD}$. For comparison of data from two independent data comparisons, unpaired $t$-test was used to determine statistical significance. For statistics on the phenotype, we used two-sided Mann-Whitney $U$-test. $(P<0.05$ $\left[{ }^{*}\right], P<0.01\left[{ }^{* *}\right]$, and $\left.\left.P<0.001{ }^{[* *}\right]\right)$. Most statistical analyses were performed using GraphPad or Excel.

\section{Data access}

The RNA-seq, ChIP-seq, and ATAC-seq data generated in this study data have been submitted to the NCBI Gene Expression Omnibus with accession number GSE106999. The proteomic mass spectrometry data are available as in Supplemental Tables S3 and S4.

\section{Acknowledgments}

We especially thank Dr. Hyobin Jeong for Bioinformatics analysis in this project. We also thank the members of the Tiwari laboratory and Calegari laboratory for their cooperation and critical feedback throughout this study. The support from the Facilities of the Queen's University Belfast, Center for Regenerative Therapies Dresden (CRTD), and Institute of Molecular Biology is 
gratefully acknowledged. This study was supported by the Deutsche Forschungsgemeinschaft (TI 799/1-3). I.M. and F.C. were supported by the CRTD, TU Dresden, and DFG CA893/9-1.

Author contributions: A.B. performed experiments, analyzed data, and wrote the manuscript. I.M. performed in utero electroporations and cell cycle analysis of cortical cells. S.K.S. assisted with obtaining the first set of observations. N.T. provided critical conceptual input to this study. B.K. provided help to A.B. during functional and biochemical analysis. J.B. performed in utero electroporations. A.S. performed analysis of single-cell transcriptome data sets. F.C. provided critical suggestions, analyzed data, and wrote the manuscript. V.K.T. designed the study, analyzed data, and wrote the manuscript. All authors read and approved the final manuscript.

\section{References}

Anders S, Huber W. 2010. Differential expression analysis for sequence count data. Genome Biol 11: R106. doi:10.1186/gb2010-11-10-r106

Aprea J, Prenninger S, Dori M, Ghosh T, Monasor LS, Wessendorf E, Zocher S, Massalini S, Alexopoulou D, Lesche M, et al. 2013. Transcriptome sequencing during mouse brain development identifies long non-coding RNAs functionally involved in neurogenic commitment. EMBO J 32: 3145-3160. doi:10 $.1038 /$ emboj. 2013.245

Arai Y, Pulvers JN, Haffner C, Schilling B, Nüsslein I, Calegari F, Huttner WB. 2011. Neural stem and progenitor cells shorten S-phase on commitment to neuron production. Nat Commun 2: 154. doi:10.1038/ncomms1155

Baker LA, Allis CD, Wang GG. 2008. PHD fingers in human diseases: disorders arising from misinterpreting epigenetic marks. Mutat Res 647: 3-12. doi:10.1016/j.mrfmmm.2008 .07 .004

Baumgart J, Grebe N. 2015. C57BL/6-specific conditions for efficient in utero electroporation of the central nervous system. I Neurosci Methods 240: 116-124. doi:10.1016/j.jneumeth .2014 .11 .004

Bertoli C, Skotheim JM, Bruin RAM de. 2013. Control of cell cycle transcription during G1 and S phases. Nat Rev Mol Cell Biol 14: 518-528. doi:10.1038/nrm3629

Bertonha FB, Barros Filho MdC, Kuasne H, Dos Reis PP, da Costa Prando E, Muñoz JJAM, Roffé M, Hajj GNM, Kowalski LP, Rainho CA, et al. 2015. PHF21B as a candidate tumor suppressor gene in head and neck squamous cell carcinomas. Mol Oncol 9: 450-462. doi:10.1016/j.molonc.2014.09.009

Bibel M, Richter J, Schrenk K, Tucker KL, Staiger V, Korte M, Goetz M, Barde YA. 2004. Differentiation of mouse embryonic stem cells into a defined neuronal lineage. Nat Neurosci 7: 1003-1009. doi:10.1038/nn1301

Bibel M, Richter J, Lacroix E, Barde YA. 2007. Generation of a defined and uniform population of CNS progenitors and neurons from mouse embryonic stem cells. Nat Protoc 2: 1034-1043. doi:10.1038/nprot.2007.147

Borrell V, Calegari F. 2014. Mechanisms of brain evolution: regulation of neural progenitor cell diversity and cell cycle length. Neurosci Res 86: 14-24. doi:10.1016/j.neures.2014.04.004

Bozzi Y, Casarosa S, Caleo M. 2012. Epilepsy as a neurodevelopmental disorder. Front Psychiatry 3: 19. doi:10.3389/fpsyt .2012 .00019

Brunmeir R, Lagger S, Seiser C. 2009. Histone deacetylase HDAC1/HDAC2-controlled embryonic development and cell differentiation. Int J Dev Biol 53: 275-289. doi:10.1387/ ijdb.082649rb
Buenrostro JD, Giresi PG, Zaba LC, Chang HY, Greenleaf WJ. 2013. Transposition of native chromatin for fast and sensitive epigenomic profiling of open chromatin, DNA-binding proteins and nucleosome position. Nat Methods 10: 1213-1218. doi: $10.1038 /$ nmeth. 2688

Calegari F. 2005. Selective lengthening of the cell cycle in the neurogenic subpopulation of neural progenitor cells during mouse brain development. J Neurosci 25: 6533-6538. doi:10 .1523/JNEUROSCI.0778-05.2005

Calegari F, Huttner WB. 2003. An inhibition of cyclin-dependent kinases that lengthens, but does not arrest, neuroepithelial cell cycle induces premature neurogenesis. I Cell Sci 116: 4947-4955. doi:10.1242/jcs.00825

Cam H, Dynlacht BD. 2003. Emerging roles for E2F: beyond the G1/S transition and DNA replication. Cancer Cell 3: 311316. doi:10.1016/S1535-6108(03)00080-1

Coe BP, Stessman HAF, Sulovari A, Geisheker MR, Bakken TE, Lake AM, Dougherty JD, Lein ES, Hormozdiari F, Bernier RA, et al. 2019. Neurodevelopmental disease genes implicated by de novo mutation and copy number variation morbidity. Nat Genet 51: 106-116. doi:10.1038/s41588-018-0288-4

Cunningham JM, Vierkant RA, Sellers TA, Phelan C, Rider DN, Liebow M, Schildkraut J, Berchuck A, Couch FJ, Wang X, et al. 2009. Cell cycle genes and ovarian cancer susceptibility: a tagSNP analysis. Br J Cancer 101: 1461-1468. doi:10.1038/sj .bjc. 6605284

Czéh B, Michaelis T, Watanabe T, Frahm J, Biurrun G de, van Kampen M, Bartolomucci A, Fuchs E. 2001. Stress-induced changes in cerebral metabolites, hippocampal volume, and cell proliferation are prevented by antidepressant treatment with tianeptine. Proc Natl Acad Sci U S A 98: 12796-12801. doi:10.1073/pnas.211427898

Dehay C, Kennedy H. 2007. Cell-cycle control and cortical development. Nat Rev Neurosci 8: 438-450. doi:10.1038/nrn2097

Dhayalan A, Tamas R, Bock I, Tattermusch A, Dimitrova E, Kudithipudi S, Ragozin S, Jeltsch A. 2011. The ATRX-ADD domain binds to $\mathrm{H} 3$ tail peptides and reads the combined methylation state of K4 and K9. Hum Mol Genet 20: 21952203. doi:10.1093/hmg/ddr107

Fietz SA, Lachmann R, Brandl H, Kircher M, Samusik N, Schröder R, Lakshmanaperumal N, Henry I, Vogt J, Riehn A, et al. 2012. Transcriptomes of germinal zones of human and mouse fetal neocortex suggest a role of extracellular matrix in progenitor self-renewal. Proc Natl Acad Sci 109: 11836-11841. doi:10 $.1073 /$ pnas. 1209647109

Florio M, Huttner WB. 2014. Neural progenitors, neurogenesis and the evolution of the neocortex. Development 141: 21822194. doi:10.1242/dev.090571

Flynn EM, Huang OW, Poy F, Oppikofer M, Bellon SF, Tang Y, Cochran AG. 2015. A subset of human bromodomains recognizes butyryllysine and crotonyllysine histone peptide modifications. Structure 23: 1801-1814. doi:10.1016/j.str .2015 .08 .004

Forneris F, Binda C, Dall'Aglio A, Fraaije MW, Battaglioli E, Mattevi A. 2006. A highly specific mechanism of histone H3-K4 recognition by histone demethylase LSD1. J Biol Chem 281: 35289-35295. doi:10.1074/jbc.M607411200

Frank CL, Tsai L-H. 2009. Alternative functions of core cell cycle regulators in neuronal migration, neuronal maturation, and synaptic plasticity. Neuron 62: 312-326. doi:10.1016/j .neuron.2009.03.029

Gaidatzis D, Lerch A, Hahne F, Stadler MB. 2015. QuasR: quantification and annotation of short reads in R. Bioinformatics 31: 1130-1132. doi:10.1093/bioinformatics/btu781 
Gatchalian J, Gallardo CM, Shinsky SA, Ospina RR, Liendo AM, Krajewski K, Klein BJ, Andrews FH, Strahl BD, van M Wely $\mathrm{KH}$, et al. 2016. Chromatin condensation and recruitment of PHD finger proteins to histone $\mathrm{H} 3 \mathrm{~K} 4 \mathrm{me} 3$ are mutually exclusive. Nucleic Acids Res 44: 6102-6112. doi:10.1093/nar/ gkw193

Gilmore EC, Walsh CA. 2013. Genetic causes of microcephaly and lessons for neuronal development. Wiley Interdiscip Rev Dev Biol 2: 461-478. doi:10.1002/wdev.89

Guerrini R, Parrini E. 2010. Neuronal migration disorders. Neurobiol Dis 38: 154-166. doi:10.1016/j.nbd.2009.02.008

Guillemot F, Molnár Z, Tarabykin V, Stoykova A. 2006. Molecular mechanisms of cortical differentiation. Eur J Neurosci 23: 857-868. doi:10.1111/j.1460-9568.2006.04626.x

Hardwick LJA, Ali FR, Azzarelli R, Philpott A. 2015. Cell cycle regulation of proliferation versus differentiation in the central nervous system. Cell Tissue Res 359: 187-200. doi:10.1007/ s00441-014-1895-8

Heinz S, Benner C, Spann N, Bertolino E, Lin YC, Laslo P, Cheng JX, Murre C, Singh H, Glass CK. 2010. Simple combinations of lineage-determining transcription factors prime cis-regulatory elements required for macrophage and B cell identities. Mol Cell 38: 576-589. doi:10.1016/j.molcel.2010.05.004

Herrup K, Yang Y. 2007. Cell cycle regulation in the postmitotic neuron: oxymoron or new biology? Nat Rev Neurosci 8: 368378. doi:10.1038/nrn2124

Homem CCF, Repic M, Knoblich JA. 2015. Proliferation control in neural stem and progenitor cells. Nat Rev Neurosci 16: 647-659. doi:10.1038/nrn4021

Huang G, Herbert J. 2005. Serotonin modulates the suppressive effects of corticosterone on proliferating progenitor cells in the dentate gyrus of the hippocampus in the adult rat. Neuropsychopharmacol 30: 231-241. doi:10.1038/sj.npp.1300609.

Huang DW, Sherman BT, Lempicki RA. 2009. Systematic and integrative analysis of large gene lists using DAVID bioinformatics resources. Nat Protoc 4: 44-57. doi:10.1038/nprot .2008 .211

Hunter S, Apweiler R, Attwood TK, Bairoch A, Bateman A, Binns D, Bork P, Das U, Daugherty L, Duquenne L, et al. 2009. InterPro: the integrative protein signature database. Nucleic Acids Res 37: D211-D215. doi:10.1093/nar/gkn785

Iacovino M, Bosnakovski D, Fey H, Rux D, Bajwa G, Mahen E, Mitanoska A, Xu Z. 2014. Inducible cassette exchange: a rapid and efficient system enabling conditional gene expression in embryonic stem and primary cells. Stem Cells 29: 15801588. doi:10.1002/stem.715

Imayoshi I, Kageyama R. 2014. bHLH factors in self-renewal, multipotency, and fate choice of neural progenitor cells. Neuron 82: 9-23. doi:10.1016/j.neuron.2014.03.018

Itoh Y, Tyssowski K, Gotoh Y. 2013. Transcriptional coupling of neuronal fate commitment and the onset of migration. Curr Opin Neurobiol 23: 957-964. doi:10.1016/j.conb.2013.08.003

Iwase S, Shono N, Honda A, Nakanishi T, Kashiwabara S-i, Takahashi S, Baba T. 2006. A component of BRAF-HDAC complex, $\mathrm{BHC} 80$, is required for neonatal survival in mice. FEBS Lett 580: 3129-3135. doi:10.1016/j.febslet.2006.04.065

Jakovcevski M, Akbarian S. 2012. Epigenetic mechanisms in neurological disease. Nat Med 18: 1194-1204. doi:10.1038/nm .2828

Jones MH, Hamana N, Shimane M. 2000. Identification and characterization of BPTF, a novel bromodomain transcription factor. Genomics 63: 35-39. doi:10.1006/geno.1999.6070

Kaldis P, Richardson HE. 2012. When cell cycle meets development. Development 139: 225-230. doi:10.1242/dev.073288
Kishi Y, Gotoh Y. 2018. Regulation of chromatin structure during neural development. Front Neurosci 12: 874. doi:10.3389/ fnins.2018.00874

Lan F, Collins RE, Cegli R de, Alpatov R, Horton JR, Shi X, Gozani O, Cheng X, Shi Y. 2007. Recognition of unmethylated histone H3 lysine 4 links BHC80 to LSD1-mediated gene repression. Nature 448: 718-722. doi:10.1038/nature06034

Lange C, Calegari F. 2010. Cdks and cyclins link $\mathrm{G}_{1}$ length and differentiation of embryonic, neural and hematopoietic stem cells. Cell Cycle 9: 1893-1900. doi:10.4161/cc.9.10.11598

Lange C, Huttner WB, Calegari F. 2009. Cdk4/cyclinD1 overexpression in neural stem cells shortens G1, delays neurogenesis, and promotes the generation and expansion of basal progenitors. Cell Stem Cell 5: 320-331. doi:10.1016/j.stem .2009.05.026

Langmead B. 2010. Aligning short sequencing reads with Bowtie. Curr Protoc Bioinformatics 32: 11.7.1-11.7.14. doi:10.1002/ 0471250953.bi1107s32

Lee JE. 1997. Basic helix-loop-helix genes in neural development. Curr Opin Neurobiol 7: 13-20. doi:10.1016/S0959-4388(97) 80115-8

Lee MG, Wynder C, Cooch N, Shiekhattar R. 2005. An essential role for CoREST in nucleosomal histone 3 lysine 4 demethylation. Nature 437: 432-435. doi:10.1038/nature04021

Li H, Handsaker B, Wysoker A, Fennell T, Ruan J, Homer N, Marth G, Abecasis G, Durbin R. 2009. The sequence alignment/Map format and SAMtools. Bioinformatics 25: 20782079. doi:10.1093/bioinformatics/btp352

Lim DA, Huang Y-C, Swigut T, Mirick AL, Garcia-Verdugo JM, Wysocka J, Ernst P, Alvarez-Buylla A. 2009. Chromatin remodelling factor Mll1 is essential for neurogenesis from postnatal neural stem cells. Nature 458: 529-533. doi:10.1038/ nature 07726

Magri L, Swiss VA, Jablonska B, Lei L, Pedre X, Walsh M, Zhang W, Gallo V, Canoll P, Casaccia P. 2014. E2F1 coregulates cell cycle genes and chromatin components during the transition of oligodendrocyte progenitors from proliferation to differentiation. I Neurosci 34: 1481-1493. doi:10.1523/JNEUROSCI .2840-13.2014

Malberg JE, Eisch AJ, Nestler EJ, Duman RS. 2000. Chronic antidepressant treatment increases neurogenesis in adult rat hippocampus. Journal of Neuroscience 20: 9104-9110. doi:10 .1523/JNEUROSCI.20-24-09104.2000

Mall M, Kareta MS, Chanda S, Ahlenius H, Perotti N, Zhou B, Grieder SD, Ge X, Drake S, Euong Ang C, et al. 2017. Myt11 safeguards neuronal identity by actively repressing many non-neuronal fates. Nature 544: 245-249. doi:10.1038/ nature 21722

Menke A, Binder EB. 2014. Epigenetic alterations in depression and antidepressant treatment. Dialogues Clin Neurosci 16: 395-404.

Mering C von, Jensen LJ, Snel B, Hooper SD, Krupp M, Foglierini M, Jouffre N, Huynen MA, Bork P. 2005. STRING: known and predicted protein-protein associations, integrated and transferred across organisms. Nucleic Acids Res 33: D433-D437. doi:10.1093/nar/gki005

Metzger E, Wissmann M, Yin N, Müller JM, Schneider R, Peters AHFM, Günther T, Buettner R, Schüle R. 2005. LSD1 demethylates repressive histone marks to promote androgen-receptor-dependent transcription. Nature 437: 436-439. doi:10 $.1038 /$ nature04020

Miles WO, Lepesant JMJ, Bourdeaux J, Texier M, Kerenyi MA, Nakakido M, Hamamoto R, Orkin SH, Dyson NJ, Di Stefano L. 2015. The LSD1 family of histone demethylases and the pumilio posttranscriptional repressor function in a complex 
regulatory feedback loop. Mol Cell Biol 35: 4199-4211. doi:10 $.1128 /$ MCB.00755-15

Monaghan CE, Nechiporuk T, Jeng S, McWeeney SK, Wang J, Rosenfeld MG, Mandel G. 2017. REST corepressors RCOR1 and RCOR2 and the repressor INSM1 regulate the proliferation-differentiation balance in the developing brain. Proc Natl Acad Sci 114: E406-E415. doi:10.1073/pnas.1620230114

Nestler EJ. 2014. Epigenetic mechanisms of depression. JAMA Psychiatry 71: 454-456. doi:10.1001/jamapsychiatry.2013 .4291

Nonaka-Kinoshita M, Reillo I, Artegiani B, Martínez-Martínez MA, Nelson M, Borrell V, Calegari F. 2013. Regulation of cerebral cortex size and folding by expansion of basal progenitors. EMBO J 32: 1817-1828. doi:10.1038/emboj.2013.96

Orford KW, Scadden DT. 2008. Deconstructing stem cell self-renewal: genetic insights into cell-cycle regulation. Nat Rev Genet 9: 115-128. doi:10.1038/nrg2269

Otani J, Nankumo T, Arita K, Inamoto S, Ariyoshi M, Shirakawa M. 2009. Structural basis for recognition of H3K4 methylation status by the DNA methyltransferase 3A ATRX-DNMT3DNMT3L domain. EMBO Rep 10: 1235-1241. doi:10.1038/ embor.2009.218

Pataskar A, Jung J, Smialowski P, Noack F, Calegari F, Straub T, Tiwari VK. 2016. NeuroD1 reprograms chromatin and transcription factor landscapes to induce the neuronal program. EMBO J 35: 24-45. doi:10.15252/embj.201591206

Pilaz L-J, Patti D, Marcy G, Ollier E, Pfister S, Douglas RJ, Betizeau M, Gautier E, Cortay V, Doerflinger N, et al. 2009. Forced G1-phase reduction alters mode of division, neuron number, and laminar phenotype in the cerebral cortex. Proc Natl Acad Sci 106: 21924-21929. doi:10.1073/pnas.0909894106

Poppy Roworth A, Ghari F, La Thangue NB. 2015. To live or let die-complexity within the E2F1 pathway. Mol Cell Oncol 2: e970480. doi:10.4161/23723548.2014.970480

Richardson L, Venkataraman S, Stevenson P, Yang Y, Moss J, Graham L, Burton N, Hill B, Rao J, Baldock RA, et al. 2014. EMAGE mouse embryo spatial gene expression database: 2014 update. Nucleic Acids Res 42: D835-D844. doi:10 $.1093 / \mathrm{nar} / \mathrm{gkt} 1155$

Robinson MD, McCarthy DI, Smyth GK. 2010. edgeR: a Bioconductor package for differential expression analysis of digital gene expression data. Bioinformatics 26: 139-140. doi:10 $.1093 /$ bioinformatics/btp616

Rubeis S de, He X, Goldberg AP, Poultney CS, Samocha K, Cicek AE, Kou Y, Liu L, Fromer M, Walker S, et al. 2014. Synaptic, transcriptional and chromatin genes disrupted in autism. $\mathrm{Na}$ ture 515: 209-215. doi:10.1038/nature 13772

Rusconi F, Grillo B, Toffolo E, Mattevi A, Battaglioli E. 2017. NeuroLSD1: splicing-generated epigenetic enhancer of neuroplasticity. Trends Neurosci 40: 28-38. doi:10.1016/j.tins.2016 .11 .002

Salomoni P, Calegari F. 2010. Cell cycle control of mammalian neural stem cells: putting a speed limit on G1. Trends Cell Biol 20: 233-243. doi:10.1016/j.tcb.2010.01.006

Sanchez R, Zhou M-M. 2011. The PHD finger: a versatile epigenome reader. Trends Biochem Sci 36: 364-372.

Sarasua SM, Dwivedi A, Boccuto L, Chen C-F, Sharp JL, Rollins JD, Collins JS, Rogers RC, Phelan K, DuPont BR. 2014. $22 \mathrm{q} 13.2 \mathrm{q} 13.32$ genomic regions associated with severity of speech delay, developmental delay, and physical features in Phelan-McDermid syndrome. Genet Med 16: 318-328. doi:10.1038/gim.2013.144

Scholz J, Besir H, Strasser C, Suppmann S. 2013. A new method to customize protein expression vectors for fast, efficient and background free parallel cloning. BMC Biotechnol 13: 12 . doi:10.1186/1472-6750-13-12

1208 GENES \& DEVELOPMENT
Shibata M, Gulden FO, Sestan N. 2015. From trans to cis: transcriptional regulatory networks in neocortical development. Trends Genet 31: 77-87. doi:10.1016/j.tig.2014.12.004

Shohayeb B, Diab M, Ahmed M, Ng DCH. 2018. Factors that influence adult neurogenesis as potential therapy. Trans1 Neurodegener 7: 4. doi:10.1186/s40035-018-0109-9

Spitz F, Furlong EEM. 2012. Transcription factors: from enhancer binding to developmental control. Nat Rev Genet 13: 613626. doi:10.1038/nrg3207

Sun M-K. 2012. Trends in cognitive sciences. Nova Science Publishers, New York.

Telley L, Govindan S, Prados J, Stevant I, Nef S, Dermitzakis E, Dayer A, Jabaudon D. 2016. Sequential transcriptional waves direct the differentiation of newborn neurons in the mouse neocortex. Science 351: 1443-1446. doi:10.1126/science .aad8361

Teo CH, Soga T, Parhar IS. 2018. Brain $\beta$-catenin signalling during stress and depression. Neurosignals 26: 31-42. doi:10.1159/ 000487764

Thakurela S, Sahu SK, Garding A, Tiwari VK. 2015. Dynamics and function of distal regulatory elements during neurogenesis and neuroplasticity. Genome Res 25: 1309-1324. doi:10 $.1101 /$ gr.190926.115

Tiwari N, Pataskar A, Péron S, Thakurela S, Sahu SK, FigueresOñate M, Marichal N, López-Mascaraque L, Tiwari VK, Berninger B. 2018. Stage-specific transcription factors drive astrogliogenesis by remodeling gene regulatory landscapes. Cell Stem Cell 23: 557-571.e8. doi:10.1016/j.stem.2018.09.008

Trapnell C, Pachter L, Salzberg SL. 2009. TopHat: discovering splice junctions with RNA-seq. Bioinformatics 25: 11051111. doi:10.1093/bioinformatics/btp120

Tsankova N, Renthal W, Kumar A, Nestler EJ. 2007. Epigenetic regulation in psychiatric disorders. Nat Rev Neurosci 8: 355-367. doi:10.1038/nrn2132

Tsuboi M, Kishi Y, Yokozeki W, Koseki H, Hirabayashi Y, Gotoh Y. 2018. Ubiquitination-independent repression of PRC1 targets during neuronal fate restriction in the developing mouse neocortex. Dev Cell 47: 758-772.e5. doi:10.1016/j.devcel .2018 .11 .018

Tsume M, Kimura-Yoshida C, Mochida K, Shibukawa Y, Amazaki S, Wada Y, Hiramatsu R, Shimokawa K, Matsuo I. 2012. Brd2 is required for cell cycle exit and neuronal differentiation through the E2F1 pathway in mouse neuroepithelial cells. Biochem Biophys Res Commun 425: 762-768. doi:10 .1016/j.bbrc.2012.07.149

Urbán N, van den Berg DLC, Forget A, Andersen J, Demmers JAA, Hunt C, Ayrault O, Guillemot F. 2016. Return to quiescence of mouse neural stem cells by degradation of a proactivation protein. Science 353: 292-295. doi:10.1126/science.aaf4802

Urdinguio RG, Sanchez-Mut JV, Esteller M. 2009. Epigenetic mechanisms in neurological diseases: genes, syndromes, and therapies. The Lancet Neurology 8: 1056-1072. doi:10.1016/ S1474-4422(09)70262-5

Vasconcelos FF, Sessa A, Laranjeira C, Raposo AASF, Teixeira V, Hagey DW, Tomaz DM, Muhr J, Broccoli V, Castro DS. 2016. MyT1 counteracts the neural progenitor program to promote vertebrate neurogenesis. Cell Rep 17: 469-483. doi:10.1016/j .celrep.2016.09.024

Visel A. 2004. GenePaint.org: an atlas of gene expression patterns in the mouse embryo. Nucleic Acids Res 32: 552D-556. doi:10 $.1093 /$ nar/gkh029

Wang Y, Wu Q, Yang P, Wang C, Liu J, Ding W, Liu W, Bai Y, Yang Y, Wang H, et al. 2016. LSD1 co-repressor Rcor2 orchestrates neurogenesis in the developing mouse brain. Nat Commun 7: 10481. doi:10.1038/ncomms10481 
Wollnik B. 2010. A common mechanism for microcephaly. Nat Genet 42: 923-924. doi:10.1038/ng1110-923

Wong M-L, Arcos-Burgos M, Liu S, Vélez JI, Yu C, Baune BT, Jawahar MC, Arolt V, Dannlowski U, Chuah A, et al. 2017. The $P H F 21 B$ gene is associated with major depression and modulates the stress response. Mol Psychiatry 22: 1015-1025. doi:10.1038/mp.2016.174

Yang YJ, Baltus AE, Mathew RS, Murphy EA, Evrony GD, Gonzalez DM, Wang EP, Marshall-Walker CA, Barry BJ, Murn J, et al. 2012. Microcephaly gene links trithorax and REST/NRSF to control neural stem cell proliferation and differentiation. Cell 151: 1097-1112. doi:10.1016/j.cell.2012.10 .043

Zhang Y, Liu T, Meyer CA, Eeckhoute J, Johnson DS, Bernstein BE, Nussbaum C, Myers RM, Brown M, Li W, et al. 2008. Mod- el-based analysis of ChIP-Seq (MACS). Genome Biol 9: R137. doi:10.1186/gb-2008-9-9-r137

Zhang C, Mejia LA, Huang J, Valnegri P, Bennett EJ, Anckar J, Asl AJ, Gallardo G, Ikeuchi Y, Yamada T, et al. 2013. The X-linked intellectual disability protein PHF6 associates with the PAF1 complex and regulates neuronal migration in the mammalian brain. Neuron 78: 986-993. doi:10.1016/j.neuron.2013.04.021

Zhang F, Xu D, Yuan L, Sun Y, Xu Z. 2014. Epigenetic regulation of Atrophin1 by lysine-specific demethylase 1 is required for cortical progenitor maintenance. Nat Commun 5: 5815. doi: $10.1038 /$ ncomms 6815

Zhang C, Tu H-L, Jia G, Mukhtar T, Taylor V, Rzhetsky A, Tay S. 2019. Ultra-multiplexed analysis of single-cell dynamics reveals logic rules in differentiation. Sci $A d v$ 5: eaav7959. doi:10.1126/sciadv.aav7959 


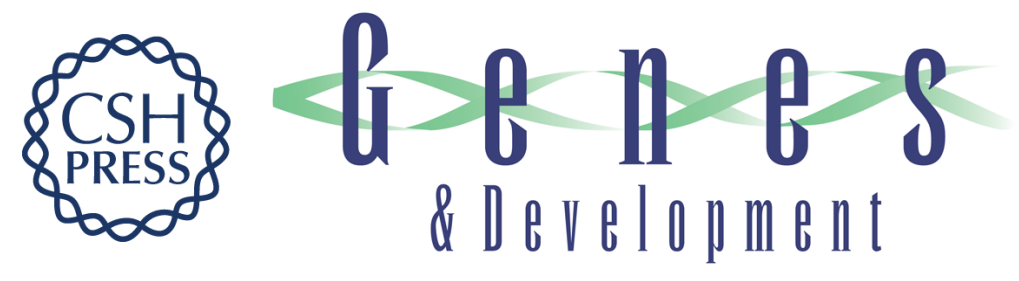

\section{Phf21b imprints the spatiotemporal epigenetic switch essential for neural stem cell differentiation}

Amitava Basu, Iván Mestres, Sanjeeb Kumar Sahu, et al.

Genes Dev. 2020, 34: originally published online August 20, 2020

Access the most recent version at doi:10.1101/gad.333906.119

\section{Supplemental http://genesdev.cshlp.org/content/suppl/2020/08/20/gad.333906.119.DC1 Material}

References This article cites 100 articles, 17 of which can be accessed free at: http://genesdev.cshlp.org/content/34/17-18/1190.full.html\#ref-list-1

Creative This article is distributed exclusively by Cold Spring Harbor Laboratory Press for the first Commons six months after the full-issue publication date (see

License http://genesdev.cshlp.org/site/misc/terms.xhtml). After six months, it is available under a Creative Commons License (Attribution-NonCommercial 4.0 International), as described at http://creativecommons.org/licenses/by-nc/4.0/.

Email Alerting Receive free email alerts when new articles cite this article - sign up in the box at the top Service right corner of the article or click here.

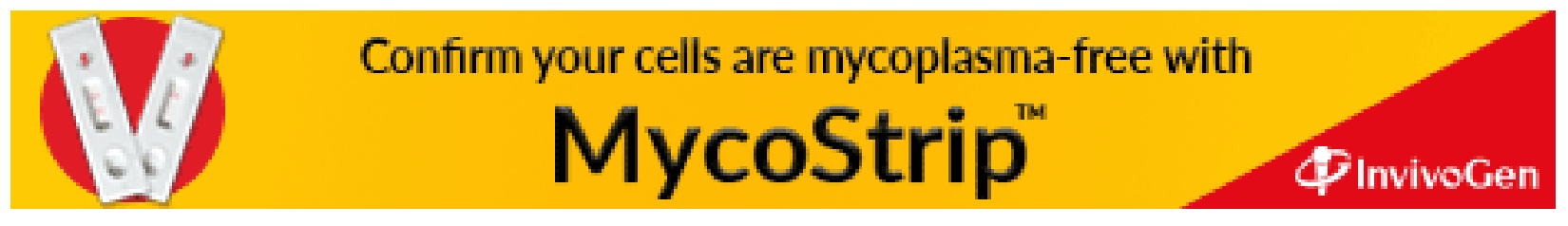

